Author version: Clim. Dyn., vol.37; 2011; 2217-2234

\title{
Processes controlling the surface temperature signature of the Madden-Julian Oscillation in the thermocline ridge of the Indian Ocean
}

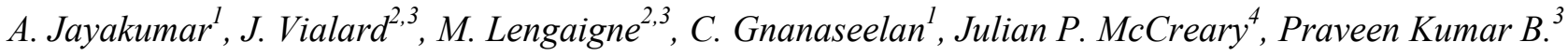

1. Indian Institute of Tropical Meteorology, Pune, India

2. Laboratoire d'Océanographie Expérimentation et Approches Numériques, CNRS, UPMC, IRD, Paris, France

3. National Institute of Oceanography, CSIR, Goa, India

4. International Pacific Research Centre / University of Hawaii, Hawaii, USA

To be submitted to Climate Dynamics

5 December 2011

Corresponding author address:

Jérôme Vialard

LOCEAN - Case 100

Case 100 - Univerité P. et M. Curie

4, Place Jussieu - 75252 Paris Cedex 05

FRANCE

E-mail: jerome.vialard@locean-ipsl.upmc.fr 


\begin{abstract}
During boreal winter, there is a prominent maximum of intraseasonal sea-surface temperature (SST) variability associated with the Madden-Julian Oscillation (MJO) along a Thermocline Ridge located in the southwestern Indian Ocean $\left(5^{\circ} \mathrm{S}-10^{\circ} \mathrm{S}, 60^{\circ} \mathrm{E}-90^{\circ} \mathrm{E}\right.$; TRIO region). There is an ongoing debate about the relative importance of air-sea heat fluxes and oceanic processes in driving this intraseasonal SST variability. Furthermore, various studies have suggested that interannual variability of the oceanic structure in the TRIO region could modulate the amplitude of the MJOdriven SST response. In this study, we use observations and ocean general circulation model (OGCM) experiments to quantify these two effects over the 1997-2006 period.

Observational analysis indicates that Ekman pumping does not contribute significantly (on average) to intraseasonal SST variability. It is, however, difficult to quantify the relative contribution of net heat fluxes and entrainment to SST intraseasonal variability from observations alone. We therefore use a suite of OGCM experiments to isolate the impacts of each process. During 1997-2006, wind stress contributed only $20 \%$ of the intraseasonal SST variability (averaged over the TRIO region), while heat fluxes contributed to $70 \%$, with forcing by shortwave radiation (75\%) dominating the other flux components (25\%). This estimate is consistent with an independent air-sea flux product, which indicates that shortwave radiation contributes $68 \%$ of intraseasonal heat flux variability. The time scale of the heat-flux perturbation, in addition to its amplitude, is also important in controlling the intraseasonal SST signature, with longer periods favouring a larger response.

There are also strong year-to-year variations in the respective role of heat fluxes and wind stress. Intraseasonal-wind stress dominates the SST signature for one (in 2001) and contributes significantly to another (in 2000) of the 5 strong cooling events identified in both observations and the model (2 in 1999, 1 in 2000, 2001 and 2002). Interannual variations of the subsurface thermal structure associated with the Indian Ocean Dipole or El Niño/La Niña events modulate the MJOdriven SST signature only moderately (by up to $30 \%$ ), mainly by changing the temperature of water entrained into the mixed layer. Our results therefore suggest that the primary factor that controls year-to-year changes in the amplitude of TRIO, intraseasonal SST anomalies is the amplitude and time-scale of the intraseasonal heat-flux perturbations.
\end{abstract}




\section{Introduction}

Over the last decade, our perception of the Indian Ocean has evolved from its being largely a climatically passive ocean to one with significant climatic influences at timescales from intraseasonal to decadal (Schott et al. 2009). Studies of air-sea interaction in the vicinity of a thermocline ridge located from $5-10^{\circ} \mathrm{S}$ in the southwestern Indian Ocean (hereafter the TRIO region) have been particularly important in causing this change of perspective, starting with the work of Xie et al. (2002). The ridge forms as a response to Ekman pumping associated with the northward weakening of the southeast trades (McCreary et al. 1993; Hermes and Reason 2008; Yokoi et al. 2008). During winter, the ridge is shallowest, with a thin mixed layer and high SST. These properties are conducive to strong air-sea interaction, since SST can easily change because of the thin mixed layer and readily available, cold water just below. Furthermore, the TRIO region is located at the western edge of the atmospheric convergence zone; as a consequence, relatively small changes in SST can induce significant changes in convection (e.g., Xie et al. 2002), with clear remote atmospheric impacts (cyclone distribution, rains over India during the following monsoon, etc.; see Vialard et al., 2009, for a review).

The TRIO region is also potentially important for the strongest, intraseasonal mode of atmospheric variability, the Madden-Julian Oscillation (hereafter MJO). The MJO is a large-scale, well-organised perturbation of atmospheric deep convection, with energetic fluctuations of tropospheric winds at periods of 30-90 days (e.g., Zhang 2005). The MJO originates in the Indian Ocean and propagates eastward at $\sim 5 \mathrm{~m} \mathrm{~s}^{-1}$ into the western Pacific. The TRIO region is one of the two regions of the Indo-Pacific with the strongest MJO SST signature, the other being the northwestern Australian basin (Duvel and Vialard 2007), and it is very close to the originating region of wintertime MJOs (e.g., Zhang 2005; Wheeler and Hendon 2004). Several studies have suggested that air-sea coupling moderately improves the structure of simulated MJOs (e.g., Waliser et al. 1999, Inness et al. 2003a, Maloney and Sobel 2004) and MJO hindcasts (Woolnough et al. 2007). Matthews (2004) suggests that ocean-atmospheric interactions may be central to MJO dynamics, while Bellenger et al. (2009) show that the intraseasonal SST variability in this region is likely to increase the large-scale organization of convective perturbations, as well as the reproducibility and the realism of the precipitation pattern. It is therefore important to understand in detail the processes responsible for the strong MJO-related sea-surface-temperature (SST) signature in the TRIO region.

Before 2000, most studies of MJO-related SST signals used infrared-based SST measurements, which are susceptible to masking by clouds and so underestimate SST signals (e.g., Sengupta and 
Ravichandran 2001; Duvel and Vialard 2007). With the advent of microwave SST products like the Tropical Rainfall Measurement Mission (TRMM) Microwave Instrument (TMI; Wentz et al 2000), much larger, intraseasonal SST signals (up $2^{\circ} \mathrm{C}$ ) were identified, particularly in the TRIO region. Some studies emphasized the role of Ekman-pumping and wind-driven entrainment in driving these SST signals (Harrison and Vecchi 2001; Vinayachandran and Saji 2008), whereas others suggested that surface heat fluxes were the primary cause (Duvel et al. 2004, Duvel and Vialard 2007, Vialard et al. 2008). Saji et al. (2006) and Han et al. (2007) suggested that both of these processes work together to produce the SST response, but did not quantify their respective importance.

Recent studies have shown that the relative importance of oceanic processes and surface heat fluxes over the TRIO region are modulated by interannual variability of the thermocline depth, $h$, thereby providing a possible explanation to reconcile the aforementioned results. Previous studies (e.g. Masumoto and Meyers 1998, Xie et al. 2002, Chowdary et al. 2009) had shown that the TRIO region exhibits strong interannual $h$ anomalies, $\Delta h$. They are generated by wind-stress curl and windstress perturbations (Gnanaseelan and Vaid 2010) in the eastern part of the Indian Ocean associated with El Niño/La Niña or the Indian Ocean Dipole (IOD, Saji et al. 1999) events, and propagate into the TRIO region as Rossby waves. Harrison and Vecchi (2001) and Duvel et al. (2004) suggested that $\Delta h$ modulates the temperature of water entrained into the mixed layer and the mixed layer depth, and hence the amplitude of MJO-driven SST events. Resplandy et al. (2009) showed that the chlorophyll response to the MJO was indeed modulated by $\Delta h$ in both observations and model experiments, suggesting that the response was due to modulation by $\Delta h$ of the nutrient-rich water input to the mixed layer. In experiments using a coupled general circulation model, Lloyd and Vecchi (2009) showed that the amplitude of cooling by oceanic processes in the TRIO region was interannually modulated, with unusually shallow $h$ resulting in stronger SST events. Finally, Izumo et al. (2009) suggested that the amplitude and timescale of the MJO itself could be modulated by $\Delta h$, with negative IODs resulting in more intense and longer timescale perturbations.

In this paper, we examine both observations and a suite of sensitivity experiments conducted with an Ocean General Circulation Model (OGCM) to investigate the aforementioned issues in more detail. Specifically, we consider the following two questions: 1) Can we quantify the relative contributions of intraseasonal heat fluxes versus wind stress (Ekman pumping and mixing/entrainment) perturbations in driving the MJO SST response in the TRIO region? 2) What controls interannual variations of the MJO-driven SST signature there: $\Delta h$, or year-to-year changes in the intraseasonal perturbations of surface fluxes, or both? 
The paper is constructed as follows. Section 2 presents the data and modelling approach used in this paper. In Section 3, we present observational analyses that investigate the controls of the intraseasonal SST response in the TRIO region. In Section 4, we report OGCM solutions that isolate and quantify the processes responsible for MJO-driven SST signals there. In Section 5, we investigate the influence of $\Delta h$ on MJO-driven SST in our OGCM experiments. In Section 6, we summarize our results and discuss their implications.

\section{Modelling approach and data}

\section{a. Data and methods}

The depths of the mixed layer and the thermocline ridge in the TRIO region are two important parameters in controlling the SST response to the MJO. We thus need to validate those fields in the model. For that purpose, we use the climatologies of mixed layer depth climatology from de Boyer et al. (2004) and of thermal stratification from the World Ocean Atlas 2005 (WOA05, Locarnini et al. 2006).

We use several recent satellite datasets to describe the surface signature of the MJO in terms of SST, winds and heat fluxes. For SST, we use optimally interpolated data from the TMI instrument produced by Remote Sensing Systems, which has been extensively used to study intraseasonal SST signature of the MJO owing to its ability to "see" through clouds. For winds, we use gridded estimates of 10-m winds from the QuikSCAT scatterometer produced at Centre ERS d'Archivage et de Traitement (CERSAT, Bentamy et al. 2003). For validation of the model computed intraseasonal wind stress, we use a blend of ERS and QuikSCAT scatterometer products from CERSAT (Bentamy et al. 2003). Daily data for each product was averaged to a common $1^{\circ}$ grid.

The air-sea flux product we use (Praveen Kumar et al., in prep) is largely derived from the ECMWF Interim Re-Analysis (ERA-I; Dee and Uppala, 2009). Turbulent fluxes (LHF and SHF) are obtained from the Coupled Ocean-Atmosphere Response Experiment (COARE3) bulk flux algorithm (Fairall et al., 2003), using ERA-interim SST, air temperature, specific humidity and wind speed. Air-temperature and specific humidity are first corrected from a temperature-dependent systematic bias on the basis of comparison with moorings from the Research Moored Array for African-Asian-Australian Monsoon Analysis and Prediction (RAMA, McPhaden et al. 2009). The surface downward shortwave flux is obtained by adding the climatology of the ISCCP product (Zhang et al. 2004) and interannual anomalies of the NOAA interpolated Outgoing Longwave 
Radiation product (Liebmann and Smith, 1996); a comparison to tropical moored array data indeed show that this is a very good estimate of the surface downward shortwave flux in the Indian Ocean. The net shortwave flux is obtained using an albedo of $6 \%$. The net longwave radiation is taken from ERA interim. The resulting daily heat flux dataset was obtained for the 1989-2009 period and interpolated onto a $1^{\circ}$ regular grid. Comparison with fluxes estimated at the RAMA and TAO mooring sites (Praveen Kumar et al. 2010) shows a better performance than other available heat flux products like the NCEP (Kalnay et al. 1996) and NCEP2 re-analyses (Kanamitsu et al. 2002) or the uncorrected ERA-I fluxes, and a similar performance to the OAFLUX product ( $\mathrm{Yu}$ and Weller, 2007).

\section{b. Modelling approach}

Our OGCM is the Modular Ocean Model Version 4 (MOM4) set up for the Indian Ocean basin between $40^{\circ} \mathrm{S}-25^{\circ} \mathrm{N}$ and $30^{\circ} \mathrm{E}-120^{\circ} \mathrm{E}$ with 30 vertical levels. The upper ocean has 15 vertical levels within a depth of 155 meters, and so the mixed layer and thermocline zones are well resolved. Bottom topography is derived from the 5-minute global topography ETOPO5 (Earth Topography-5 minute) database. The zonal resolution is $1^{\circ}$ and the meridional resolution varies from $0.33^{\circ}$ at equator to $0.7^{\circ}$ at $25^{\circ} \mathrm{N}$ and $1.5^{\circ}$ at $40^{\circ} \mathrm{S}$. Vertical mixing is based on the K-profile parameterization scheme (KPP; Large et al., 1994), with Bryan-Lewis background diffusivity (Bryan and Lewis 1979). Horizontal friction is based on the shear-dependent Smagorinsky viscosity following Griffies and Hallberg (2000). Temperature and salinity at the southern and eastern boundaries are restored to monthly climatologies of Levitus (1998). Details of the model are provided in Thompson et al. (2006).

The model is initialized using temperature and salinity from Levitus (1998), and spun up for a 20-year period using climatological forcing (Large and Yeager 2004). Subsequently, it is integrated over the 1958-1995 period using the NCAR-corrected, Interannual Forcing (CIAF) data sets from the Common Ocean-ice Reference Experiments (CORE) (Large and Yeager 2004). The control experiment (hereafter CTL) is restarted from the MOM4 solution and run for the 1996-2006 period using the same forcing product. During all the integrations, air-sea fluxes are computed interactively via bulk formulae, using model SST and specified 10-m wind, air-temperature, specific-humidity, and shortwave- and longwave-radiation fields. Thompson et al. (2008) validated the response in the northern Indian Ocean of a prior solution to the same model, except for a different time period than ours.

We perform a series of sensitivity experiments to evaluate the importance of different physical 
processes on SST intraseasonal variability in the TRIO region (see Table 1). Specifically, we store the solar (shortwave) and non-solar (sensible + latent + longwave) heat flux components as well as wind stress computed by the model during the CTL, and then perform a series of sensitivity experiments with modified versions of these forcing fields. Several of the tests involve filtering to remove intraseasonal variability from the forcing fields. Toward that end, we filter the various forcing fields using a 120-day low pass filter ${ }^{1}$. This approach is similar to the one followed by Han et al. (2007) and Saji et al. (2006), who used 105- and 200-day cutoffs, respectively. We repeated the simulations and analyses of this paper with 90-day, low-passed-filtered forcing fields and obtained similar results, the primary difference being that the 30-120 day filter extracts larger amplitude MJO perturbations.

Table 1 provides a list of the sensitivity experiments in this paper. The NO_ISO_STRESS experiment retains the full spectrum of heat flux forcing, but has low-passed wind stress forcing (Fig. 1a) to eliminate the influence of intraseasonal Ekman pumping, mixing at the bottom of the mixed layer and entrainment. The NO_ISO_FLX experiment still has full wind-stress forcing, but all the solar and non-solar components of the heat flux forcing are low-passed to eliminate the influence of intraseasonal flux forcing (Figs. 1b and 1c). The NO_ISO_SW experiment further attempts to isolate explicitly the effect of shortwave heat-flux variations, forcing the model with full wind stress and non-solar heat flux but filtering out intraseasonal variations of the net shortwave radiation (Fig. 1c). The NO_ISO experiment forces the model with wind-stress and heat-flux (shortwave and net) that are both low-passed. To test the effect of interannual variations of the subsurface thermal structure, a final experiment, NO_INT_STRESS, is forced by the wind stress from CTL except without interannual anomalies, that is, by the seasonal climatology of the CTL wind stress plus high-passed, wind-stress variations from CTL. All sensitivity experiments were run over 1996-2006, from the same initial condition as in the CTL experiment. In this paper, we analyze model results over the 1997-2006 period.

The difference between the SST in the reference run and the filtered runs allows estimating the

\footnotetext{
${ }^{1}$ We use filtering in Fourier space in this paper. Time series are converted into Fourier coefficients using a Fast Fourier Transform (FFT), and all coefficients corresponding to frequencies that we wish to remove are set to zero before performing an inverse FFT. This approach works efficiently for an infinite time series, but results in spectral leaking of frequencies close to the cutoff frequency. Comparison with other classical filtering approaches with similar cutoff frequencies (digital filtering or a Hanning filter) produced very similar filtered series.
} 
SST signals associated with intraseasonal wind stresses, heat fluxes, and internal intraseasonal variability. These three components do not add up exactly to the SST variability in the control run because of non-linearities: we hence estimate this (small) component as the residual. We hence can decompose SST variability in the control into the contributions from intraseasonal wind stress, intraseasonal heat fluxes, internal variability and non-linearities. All of these contributions are SST (in ${ }^{\circ} \mathrm{C}$ ):

$$
\mathrm{SST}^{\prime}=\mathrm{SST}_{\tau}{ }^{\prime}+\mathrm{SST}_{\mathrm{Q}^{\prime}}+\mathrm{SST}_{\mathrm{F}}{ }^{\prime}+\mathrm{SST}_{\mathrm{r}}{ }^{\prime}
$$

where the primes indicate the intraseasonal SST variability obtained by filtering in the time domain. The first two terms on the r.h.s. of (1) are obtained from the differences $\mathrm{SST}_{\tau}{ }^{\prime}=\mathrm{SST}^{\prime}{ }_{\mathrm{CTL}}-$ $\mathrm{SST}_{\text {NO_ISO_STRESS }}^{\prime}$ and $\mathrm{SST}_{\mathrm{Q}}{ }^{\prime}=\mathrm{SST}^{\prime}{ }_{\mathrm{CTL}}-\mathrm{SST}_{\text {NO_ISO_FLX; }}^{\prime}$ they estimate the contribution of windstress and heat-flux forcing to intraseasonal variability respectively. Term $\mathrm{SST}_{\mathrm{F}}$, defined by $\mathrm{SST}_{\mathrm{F}}$ ' $=\mathrm{SST}^{\prime}{ }_{\mathrm{NO}} \mathrm{ISO}$, is the residual intraseasonal variability remaining in the NO_ISO experiment. It arises from three sources: internally generated oceanic variability (e.g., Zhou et al. 2008), intraseasonal freshwater forcing, and filtering residual. The last contribution arises because no filter is perfectly selective, and so there will be residual variability in the forcing of the sensitivity experiments at periods close to 120 days. To minimize this error, we use a slightly shorter cutoff period for extracting the SST intraseasonal response (30-100 day bandpass filter to calculate the primed quantities in Eq. 1) than the one used to low-pass the forcing of the sensitivity experiments (120 days). This approach reduces the part of the intraseasonal variance in $\mathrm{SST}_{\mathrm{F}}{ }^{\prime}$, but results are quantitatively close even if a 30-120 day bandpass filter is used in (1). Finally, term $\mathrm{SST}_{\mathrm{r}}{ }^{\prime}=\mathrm{SST}^{\prime}-$ $\left(\mathrm{SST}_{\tau}{ }^{\prime}+\mathrm{SST}_{\mathrm{Q}}{ }^{\prime}+\mathrm{SST}_{\mathrm{F}}{ }^{\prime}\right)$ is any remaining intraseasonal $\mathrm{SST}$ variability that exists because of nonlinearities, which we will call 'error." Table 2 shows that the contributions from $\mathrm{SST}_{\mathrm{F}}$ ' and $\mathrm{SST}_{\mathrm{r}}$ ' are both weak, and they are weakly correlated to the total SST variability $\mathrm{SST}^{\prime}$, hence justifying the approach above.

One of the objectives of this paper is to provide a precise quantification of the contributions of various processes to the total intraseasonal SST variability SST'. Toward that end, we obtain regression coefficients of the various contributions in (1) (in $\left.{ }^{\circ} \mathrm{C}\right)$ to the total SST intraseasonal variability $\mathrm{SST}^{\prime}$ (also in ${ }^{\circ} \mathrm{C}$ ). These non-dimensional coefficients are computed for the entire experiment (Table 2) but also separately for each December-March season (Figures 5a, 9, 10, 11b) in order to quantitatively summarize the contribution of a specific process for each year. By construction, the coefficients for the processes in (1) add up to 1. We will give these coefficients as percentages in the paper: they always sum to $100 \%$ but can be negative for a process that has a 
negative correlation to the total variability.

\section{c. Model validation}

In this section, we validate the intraseasonal component of the wind product used to force the model, as well as the model's vertical stratification and intraseasonal SST variability in the TRIO region.

Figure 1 suggests that the model intraseasonal zonal wind stress variability is underestimated compared to scatterometer data, and that the net heat flux variability is underestimated compared to TropFlux data. The model uses the ISCCP-derived shortwave heat fluxes, which is one of the best estimates of surface shortwave fluxes data available over the Indian Ocean (Praveen Kumar et al. 2010). Quantitatively, the zonal wind stress variability in the intraseasonal band (30-100 or 30-120 day bandpass-filtered) is underestimated by $\sim 30 \%$ over the December-March season, and is in phase with the scatterometer winds (correlation coefficient of $\sim 1$ ). This $30 \%$ underestimation may however be pessimistic, since comparison with in situ data suggest that Quickscat overestimates winds over the Indian Ocean (Satheesan et al. 2007). The non-solar heat flux (dominated by latent heat flux) intraseasonal variability has roughly the same amplitude as TropFlux data (standard deviation ratio of $\sim 1$ ) but with some phase disagreement (correlation coefficient of $\sim 0.7$ ).

The thermal stratification and mixed layer depth (hereafter MLD) are two potentially important factors in controlling the amplitude of the MJO SST signature in the TRIO region (e.g., Harrison and Vecchi, 2001; Duvel et al. 2004). Figure 2 provides a validation of these two parameters during boreal winter (December to March). The model is able to reproduce the observed minima in MLD, but with some systematic bias. The MLD averaged over the TRIO region is $21 \mathrm{~m}$ against $26 \mathrm{~m}$ in observations, an underestimation of about $20 \%$. The thermal stratification near the bottom of the mixed layer is a critical parameter for entrainment and Ekman pumping. The model is too warm at all depths but the thermal stratification below the mixed layer (between 20 and $70 \mathrm{~m}$ ) is quite comparable to the observed climatology (Fig. 2c). Consequences of these biases are discussed in Section 6.

Figure 3 shows a comparison between the December-March amplitude of intraseasonal SST variability in the model and observations. The model does not simulate the maxima in SST variability west of $55^{\circ} \mathrm{E}$ and north of $5^{\circ} \mathrm{S}$, which are associated with 26-day, mixed Rossby gravity wave variability (e.g., Tsai et al., 1992), but our study is not focused on this region. There are in general several regions where the model does underestimate the intraseasonal variability of the sea surface temperature. This is easily understandable since the model resolution $(\sim 100 \mathrm{~km})$ is smaller 
than the first baroclinic Rossby radius of deformation poleward of $\sim 10^{\circ}$ (Chelton et al. 1998). The model hence does not resolve eddy variability, which contribute to intraseasonal SST variability, at those latitudes. We will discuss the impact of the model resolution further in the discussion section. Despite those obvious flaws, the solution is able to reproduce a clear maximum of intraseasonal SST variability in the TRIO region (Figure 3) in December-March. It not only reproduces the spatial pattern of variability but also the amplitude, with the standard deviations of SST averaged over the region being $0.28^{\circ} \mathrm{C}$ and $0.27^{\circ} \mathrm{C}$ for the control experiment and from TMI observations, respectively (see Table 2).

Figure 4 displays the average intraseasonal variability within the TRIO region, and shows good agreement between the observed and simulated phase of the intraseasonal SST perturbation, with a correlation coefficient of 0.80 for the entire time series and of 0.86 for December-March period. There is a strong cooling event in early 1997, but no microwave SST observations to support it. There are otherwise 5 clear cooling events during the record covered by both the model and observations: 2 in 1999 (Harrison and Vecchi 2001, Duvel et al. 2004), one in 2000, one in 2001 and the strongest event in 2002 (Vinayachandran and Saji, 2008 ).

Our control experiment thus has a reasonable mean state and it accurately reproduces the intraseasonal SST variability within the TRIO region. We are therefore confident that it can be used to assess the importance of various processes controlling the intraseasonal SST variability there.

\section{Observed intraseasonal variability in the thermocline ridge, 1999-2008}

In this section, we briefly review observations of intraseasonal variability from 1999-2008, in order to provide a background for the discussion of modelling results in Sections 4 and 5. A simplified equation for the evolution of mixed-layer temperature is

$$
\frac{\partial T}{\partial t}=\underbrace{\frac{Q_{0}}{\rho c_{p} h}}_{(a)}-\underbrace{\frac{F_{-h}}{\rho c_{p} h}-w_{e} \frac{\left(T-T_{-h}\right)}{h}}_{(b)} \underbrace{u \frac{\partial T}{\partial x}-v \frac{\partial T}{\partial y}}_{(c)} .
$$

Here, $h$ is the mixed-layer thickness, $\rho c_{p}$ is the volumetric heat capacity of seawater, $T$ is the average mixed-layer temperature, and $u$ and $v$ are the mixed-layer currents. $Q_{0}$ is the net surface heat flux, corrected from the fraction of the solar heat flux that penetrates below the bottom of the mixed layer. 
The terms $F_{-h}$ and $T_{-h}$ are respectively the turbulent heat flux and the temperature just below the base of the mixed layer, and $w_{e}=\partial h / \partial t+w(-h)$ is the entrainment velocity into the mixed layer. Term (a) describes the effect of atmospheric heat fluxes, (b) is the cooling by subsurface oceanic processes (mixing, entrainment, upwelling), and (c) is the lateral temperature advection. A previous observational study in this region (Vialard et al. 2008) suggested that, although lateral advection is not negligible in this region, it does not appear to be correlated with the MJO signature and hence contributes weakly to the heat budgets at the MJO timescale. This is confirmed by modelling studies, which found little influence of lateral advection at the spatial and temporal scales of the MJO (Duvel et al. 2004, Vinayachandran and Saji 2008).

Figure 5 illustrates various properties of observed intraseasonal perturbations over the TRIO region for 1999-2008. During that period, there were 4 large events during 1999, 2001, 2002 and 2008, for which the peak-to-peak amplitude was $\sim 1^{\circ} \mathrm{C}$ or more. To visualize better the typical amplitude and phase of the atmospheric perturbations related to the SST events, Figure 6 shows a regression of intraseasonal surface heat flux, wind, and SST to SST intraseasonal variability within the TRIO region ${ }^{2}$. The typical timescale of the perturbations is 50-60 days (Fig. 6), although large amplitude events tend to have a longer timescale (Fig. 5), in agreement with the results of Saji et al. (2006) and Izumo et al. (2009). Typical peak-to-peak amplitude of the perturbations is $\sim 0.6^{\circ} \mathrm{C}$ (SST), $3 \mathrm{~ms}^{-1}$ (wind) and $50 \mathrm{Wm}^{-2}$ (net heat fluxes). Regression coefficient ${ }^{3}$ between each component and the net heat flux perturbation indicate that $68 \%$ of the latter is due to the shortwave flux (i.e., to less downward surface solar heat flux during active, cloudy phases of the MJO) and 39\% to latent heat flux (i.e., to more evaporation during the active, windy phase of the MJO). The scatterplot of Figure 7e indicates that the amplitude of the shortwave perturbation is generally quite comparable to the one of latent heat flux. The lesser influence of the latent heat flux in Figure 6 is hence due to a more variable phasing of the latent heat flux perturbation with regard to SST (the

2 The regression index (30-100 day filtered average TRIO SST) is normalized by its standard deviation, and the regression coefficients are hence expressed in physical units $\left(\mathrm{ms}^{-1}\right.$ for wind, $\mathrm{Wm}^{-2}$ for fluxes and ${ }^{\circ} \mathrm{C}$ for SST). The time series are filtered first, and then only the December-March values are considered to perform the regression.

${ }^{3}$ We remind that the percentage of variability obtained from regression coefficient sum up to $100 \%$ when all components of the fluxes are added, but can be negative. Here $68 \%+39 \%=107 \%$ because the sum of the sensible and longwave contributions contribute negatively $(-7 \%)$ to net heat flux variability. 
maximum lagged correlation between SST and latent heat flux is $\sim 0.4$ against $\sim 0.7$ for shortwave flux). This difference is explained by the fact that the wind pattern is more variable than the convection pattern from one winter MJO event to the other (Duvel and Vialard 2007).

The dominant role of the shortwave perturbation is in agreement with results from Shinoda and Hendon (1998) but contradicts the results of Han et al. (2007). The sensible and longwave heat-flux perturbations are weak $\left(\sim 5 \mathrm{Wm}^{-2}\right)$ and tend to cancel each other (they represent, respectively, $7 \%$ and $-14 \%$ of the total variability). Sensible heat losses are indeed larger during the windy, active MJO phase, but they are compensated by weaker heat losses by infrared radiation, the latter mostly due to the downward component of longwave radiation (i.e., to the greenhouse effect of clouds during the active phase). The regressed Ekman pumping velocity is very weak ( $\sim 0.1 \mathrm{~ms}^{-1}$, not shown). Although there are significant variations of the Ekman pumping velocity associated with the SST events $\left(\sim 0.5 \mathrm{~ms}^{-1}\right.$ peak-to-peak, Fig. 5$)$, they have a varying phase relation with the events (see Figure 5d and the 2008 event for example, where Ekman velocity is initially almost out-of-phase with SST and later almost in-phase). Ekman pumping depends quite critically on the wind stress curl, and hence on the wind pattern as well as its intensity. The varying phase of the Ekman pumping relative to the SST is therefore likely explained by the varying wind patterns of wintertime MJOs (Duvel and Vialard 2007).

To investigate the physical processes (air-sea fluxes or oceanic vertical processes) responsible for SST perturbations, we estimate some terms in (2). If one keeps only the term (a) in equation (2), integration and time filtering in the intraseasonal domain result in:

$$
T^{\prime}(t)=\left(\int_{0}^{t} \frac{Q_{0}}{\rho c_{p} h} d \tau\right)^{\prime}
$$

Since long-term observations of $h$ are not available within the TRIO region, we simply set $h=27.6$ m, its climatological value for December-March, from de Boyer et al. (2004), thereby representing the mixed layer as a constant thickness "slab." The blue curve in Fig. 5a plots $T^{\prime}$ from (3). Consistent with previous similar analyses (e.g., Duvel et al. 2004, Duvel and Vialard, 2007), there is good agreement between $T^{\prime}$ and observed SST (a correlation of 0.86, Fig. 7a) except that the amplitude of the former is underestimated, the overall regression coefficient being 0.52 with values varying from 0.32 to 0.78 depending on the time of year. This underestimation can be due either to: a) neglected physical processes such as entrainment; b) variations of the mixed layer depth; or c) errors in the air-sea flux product. As we will see in Section 4, neglecting mixed layer depth variations in the model does not degrade significantly the regression coefficient to $T^{\prime}$, which 
suggests that neglecting the mixed layer depth variations (point b above) is not a significant source of error in the observational approach we used here.

An important point to note in Figure 5 is that the amplitude of the flux perturbation is not directly proportional to the SST response. Indeed, as indicated in (3), the SST response is proportional to the time integral of the heat flux, and hence is enhanced for longer-lasting forcing events. For example, the 2003 event has net-heat-flux perturbations with a similar amplitude as for the 2001 event, but with a shorter timescale (Fig. 5b); as a result, the flux-driven SST perturbations are larger in 2001 than in 2003 (Fig. 5a). Similarly, the large-amplitude heat-flux perturbation in March 2005 has a relatively small SST response in comparsion to the smaller-amplitude, but longer timescale, flux perturbation in 2001. The timescale of the flux perturbation is therefore an important parameter in controlling the amplitude of the intraseasonal SST response.

We cannot as easily estimate terms (b) in (1), because of the lack of subsurface data. The vertical speed at the bottom of the mixed layer is indeed difficult to evaluate, except for the Ekman pumping component $w_{e k}=\operatorname{curl}(\tau / \rho f)$, and so is the turbulent heat flux at the bottom of the mixed layer $F_{-h}$. We can, however, investigate whether the amplitude of the intraseasonal SST signal and simplified diagnostics of the oceanic response are related. Foltz et al. (2010) have shown, for example, that there is good agreement between the cube of friction velocity, $u^{*}=(\tau / \rho)^{1 / 2}$, and the turbulent flux at the bottom of the mixed layer (mixing and entrainment) in the region at the seasonal time scale. Fig. $7 \mathrm{~b}$ shows a scatterplot between the amplitude of the intraseasonal events and the 30-100 day filtered time integral of $u^{*^{3}}$. The very good correlation (0.81) suggests that entrainment and mixing are important factors in the intraseasonal, upper-ocean heat budget. One exception is the 1999 event discussed by Harrison and Vecchi (2001) and Duvel et al. (2004), for which the time integral of $u^{* 3}$ is very weak (Fig. 7d), hence suggesting a weak effect of turbulent flux at the bottom of the mixed layer for this event. For other years, since $u^{*}$ and the heat-flux perturbations are themselves highly correlated (0.87, see Fig. 7 d), we feel that it is difficult to evaluate the respective role of heat flux forcing and vertical mixing purely from observations. Our model sensitivity experiments (section 4) will therefore help in this respect.

Nevertheless, observations can help us to resolve the potential influence of Ekman pumping at the intraseasonal timescale. As mentioned earlier, there is no systematic phase relation between Ekman pumping velocity and SST perturbations, indicating that Ekman pumping probably does not play a systematic role in the intraseasonal SST perturbations in the TRIO region. The scatterplot of Fig. $7 \mathrm{c}$ confirms that there is no relation between intraseasonal Ekman pumping and the amplitude of 
the SST perturbation. On the basis of observations, we can therefore exclude a systematic impact of Ekman pumping on intraseasonal SST variability.

The largest sea-level anomalies during December-March over the period are found in 1999 (strong negative anomaly), 2003, 2005 (mild positive anomalies), 1998 and 2007 (strong positive anomaly). All of these years are associated with either IOD and/or El Niño/La Niña events (there was both a La Niña and negative IOD in 1998; there were El Niño events in both 2002 and 2004; there were both a moderate El Niño and a positive IOD in 2006). Several papers have hypothesized that shallow thermocline (i.e. negative SLA) anomalies favour larger SST intraseasonal perturbations. There is indeed a tendency for smaller SST intraseasonal perturbations when the thermocline is deeper (Fig. 7f; correlation of -0.45 marginally significant at the $83 \%$ level), although there are also considerable variations in SST amplitude that depend on the local atmospheric forcing.

In this section, we have shown that there is generally a good agreement between observed SST anomalies and those obtained by integrating intraseasonal net heat fluxes. We also noted that longerlasting heat-flux perturbations induce a larger SST response. Observations show that Ekman pumping does not play a systematic role in the intraseasonal SST perturbations. The role of turbulent processes (mixing and entrainment) may still be significant, but it is difficult to separate their effects from those due to heat flux because the two forcings are correlated. Finally, it is also difficult to establish a potential control of intraseasonal SST variability by the interannual variability in the thermal structure based on observations only. In the next two sections, we use specifically designed numerical experiments to address these issues.

\section{Processes controlling the SST signature of the MJO}

In this section, we report sensitivity experiments to our OGCM that are designed to evaluate the relative importance of atmospheric heat fluxes (term $a$ in Eq. 2) and oceanic processes (term $b$ in Eq. 2) in driving intraseasonal SST variability in the TRIO region. We also investigate the relative influence of solar and non-solar flux (mostly latent heat flux, Fig. 5) on intraseasonal SST. In this paper, we use sensitivity experiments to derive the SST response associated with MJO heat flux and wind stress forcing. Although these two forcings will respectively primarily act through terms (a) and (b) in equation (2), they may also be associated with lateral advection associated with, e.g., lateral advection of the SST perturbation by the mean currents. In the present study, we do not 
explicitly compute the heat budget terms in equation (2) but rather quantify the overall effect of MJO induced heat fluxes and wind stresses.

Fig. 8 shows estimates of the amplitude of December-March intraseasonal SST variability caused by various processes, following the methodology introduced in Section $2 \mathrm{~b}$, but not its phase relative to the total variability, that is, whether it contributes positively or negatively to the SST variability in the region. The figure is hence complemented by Table 2, which lists linear regression coefficients in the TRIO region between the variability associated with each process and the average SST intraseasonal variability. These coefficients thus estimate the contribution of each process to the total variability. The largest contribution is from heat fluxes, accounting for $70 \%$ of the total variability (Table 2). Although wind stresses can locally have a large contribution (Fig. 8d), its average contribution is only $19 \%$ of the total variability, that is, 3-4 times smaller than the contribution from net heat flux. The residual and error terms are systematically smaller than all of the other terms for all the years, suggesting that the approach described in Section $2 \mathrm{~b}$ is valid. The two terms contribute about $11 \%$ of the total variability. Thus, $11 \%$ our error bar on the estimation of the relative importance of each process; however, Figure $9 \mathrm{~b}$ shows that the sum of the heat-flux and wind-stress contributions are a very good estimate of the total SST variability for each year.

The overall influence of intraseasonal wind stress is hence 3-4 times smaller than that of heat fluxes. Fig. 9a illustrates the year-to-year variations in the relative influence of the two processes. The phase agreement with the total SST variability is generally much better for the flux than for the wind stress contribution. Although heat-flux forcing generally dominates the SST intraseasonal variability, there are a few specific years where fluxes and oceanic processes have roughly comparable influence (2000, 2001 and 2006). There are 5 clear cooling events during the record covered by both the model and observations: 2 in 1999 (Harrison and Vecchi 2001, Duvel et al. 2004), one in 2000, one in 2001 and the strongest event in 2002 (Vinayachandran and Saji, 2008 ). Amongst these events, there is one occurrence (2000) where wind-stress driven SST signature dominate and one (2001) where it contributes significantly. Although wind-stress on average only contributes to $\sim 20 \%$ of the total SST MJO signature in the TRIO region, it hence can occasionally be the dominant process for a specific event.

In the previous section, we have used a so-called "slab mixed-layer" approach (i.e., a climatological mixed layer depth) to evaluate the contribution of heat fluxes to observed SST variability. The modelling approach that we use allows us to estimate the limitations of this approach: we have computed the flux contribution using the same approach as for the observations in Figure 9c. As shown from Figure 9c, neglecting intraseasonal and interannual mixed-layer variations 
does not degrade strongly the estimate of SST intraseasonal variability: while the regression coefficient of the heat-flux contribution to the total variability is 0.7 , the one computed from the "slab mixed layer" approach is 0.66. Mixed layer depth variability is hence not an important parameter for a precise estimation of the SST intraseasonal variability. This is probably because the shallow thermocline in the TRIO region prevents large variability of the mixed layer depth, as suggested in Duvel et al. (2004).

We saw in the previous section that the observed, intraseasonal heat-flux perturbations in the TRIO region are $68 \%$ due to shortwave radiation. Because of the shortwave penetration below the mixed layer, however, it is not obvious how this division impacts SST. In our model, SST intraseasonal variability forced by the shortwave flux is $75 \%$ of that forced by the total heat flux (Table 2). The relative roles of the latent and shortwave heat fluxes display some interannual variations (Fig. 10) with shortwave heat-flux contribution ranging from 59 to $94 \%$. In most cases, then, the shortwave heat-flux perturbation is the main factor in influencing the intraseasonal SST variability in our experiments, in contrast to the results of Han et al. (2007). We will return to this point in the discussion section.

In this section, we have shown that atmospheric intraseasonal heat fluxes are the dominant forcing of intraseasonal SST variations during 1997-2006, with a contribution four times larger than that of wind stress. Although the effect of wind stress can be important locally within the TRIO region, and its average impact over the entire region is equal to that of heat flux only for the 2000 event. In the model, the heat-flux forcing is largely due to perturbations of shortwave radiation over 1997-2006 (75\%), roughly consistent with the estimates from an independent heat flux product $(68 \%)$.

\section{Control by interannual variability of the thermocline}

In this section, we investigate whether interannual anomalies of thermocline depth influence the amplitude of the intraseasonal SST signature, as suggested by Harrison and Vecchi (2001), Duvel et al. (2004), and Resplandy et al. (2009). Specifically, we discuss experiment NO_INT_STRESS and its difference from CTL. Experiment NO_INT_STRESS retains the same heat-flux forcing as CTL but the wind-stress forcing is by climatological plus high-pass-filtered winds from CTL, that is, the forcing excludes interannual variations of the wind stress. 
Figure 11a compares sea level in CTL minus NO_INT_STRESS, which, to the extent that the response is linear, extracts the response to interannual wind stress forcing, against observed sea level interannual anomalies (SLA). There is generally a good match with observed SLA, showing that our strategy to remove interannual subsurface variability in NO_INT_STRESS is successful. The two curves indeed match quite well during the large positive SLAs after the 1997 and 2006 El Niño/IOD events, and during the large negative anomaly that follows the 1998 La Niña/negative IOD event, although the negative anomaly is underestimated by about one third in January 1998-March 1999. The model also reproduces fairly well the mild positive sea level anomalies in 2003 and 2005, which follow moderate El Niño events in the Pacific in 2002-2003 and 2004-2005. On the other hand, the model produces a large negative sea-level anomaly in 2001, whereas almost neutral conditions prevail in the observations.

The amplitude of the intraseasonal SST perturbations is indeed modulated by sea level anomalies, as demonstrated in Fig. 11b, with regression coefficients between NO_INT_STRESS and CTL varying from 0.47 (2001) to 1.27 (1998). If we exclude the year 2001 (for which the sea-level response to interannual wind stress is too large, as discussed above), the regression coefficient varies between 0.70 and 1.27 (i.e., an amplitude modulation of up to 30\%). The modulation is such that negative sea-level anomalies favour a larger intraseasonal SST response in 1997, 1999-2002, and 2006 and vice versa in 1998 and 2003-2005, consistent with hypotheses from previous studies (Harrison and Vecchi 2001, Duvel et al 2004, Vialard et al. 2009, Lloyd and Vecchi 2009, Resplandy et al. 2009).

There are two possible processes that might explain the modulation of the intraseasonal SST response by interannual variations of the subsurface thermal structure. First, as suggested by Duvel et al. (2002), the thermocline is so shallow in the TRIO region that it likely exerts a strong control on mixed-layer thickness: A thinner (thicker) mixed layer has a smaller (larger) heat capacity and is hence more swiftly (slowly) cooled or heated by anomalies of either air-sea fluxes or subsurface processes (the terms proportional to $1 / h$ in Eq. 2). Second, as suggested by Harrison and Vecchi (2001), a shallow thermocline brings cooler water to the base of the mixed layer (i.e. a lower $T_{-h}$ in Eq. 1) and strengthens the impact of vertical mixing (term $b$ in Eq. 2).

To investigate these two possibilities, Figures $12 \mathrm{a}$ and $12 \mathrm{~b}$ provide, respectively, scatterplots of i) MLD against SLA in the TRIO region in the CTL experiment, and ii) MLD in the CTL experiment against MLD in the NO_INT_STRES experiment. Figure 12a suggests that there is indeed a weak control of the MLD by SLA, with a correlation of 0.62 and regression coefficient of $0.23 \mathrm{~m} / \mathrm{cm}$. On the other hand, Figure $12 \mathrm{~b}$ shows that there is a strong coherent relation between the MLDs in CTL 
and NO_INT_STRESS, which suggests that the correlation in Figure 12a might be coincidental. The figure suggests that interannual MLD variability in the TRIO region is probably controlled by other factors (e.g., local interannual changes in atmospheric momentum and buoyancy fluxes), which also happen to be correlated with the heat content change. The modulation of the MLD by interannual variations of the subsurface thermal structure is hence not responsible for the varying intraseasonal SST response in the TRIO region.

We estimate the temperature jump at the bottom of the mixed layer as the mean mixed-layer temperature minus the temperature $10 \mathrm{~m}$ below the mixed layer; as in Foltz et al. (2010). There is a strong and very coherent relation between this temperature jump and sea-level anomalies in the TRIO region (Figure 12c, correlation of -0.99). If we exclude 2001 (because of the bias in model SLA during that year), the temperature jump at the bottom of the mixed layer varies by a factor of 3 between years with a deep thermocline $\left(\Delta T \approx 0.3^{\circ} \mathrm{C}\right.$ in 1998) and years with a shallow thermocline $\left(\Delta T \approx 1^{\circ} \mathrm{C}\right.$ in 1999). Despite this strong modulation of $\Delta T$, the control of intraseasonal SST amplitude by the oceanic stratification is relatively weak (about 20\%). This apparent contradiction is explained by the relatively weak role $(\sim 20 \%)$ of upwelling and entrainment against atmospheric heat fluxes in the overall intraseasonal SST perturbation, as demonstrated in Section 3.

The results in this section suggest that interannual subsurface thermal variability associated with IOD/ENSO events did modulate the SST signature of the MJO in the TRIO region by up to $30 \%$ over the 1997-2006 period. Changes in the temperature vertically advected and/or entrained into the mixed layer seem to be the main process responsible for this interannual modulation. This modulation is quite weak with respect to the large-amplitude variation of the SST response, suggesting that the conclusions that year-to-year differences in the properties of the MJO-induced, surface heat-flux perturbation is the main factor that controls the intraseasonal SST response in the TRIO region.

\section{Summary and Discussion}

In this paper, we have used observations and sensitivity experiments with an OGCM (MOM4) to explore the mechanisms controlling intraseasonal SST variability in the TRIO region $\left(5^{\circ} \mathrm{S}-10^{\circ} \mathrm{S}\right.$, $60^{\circ} \mathrm{E}-90^{\circ} \mathrm{E}$ ), and its year-to-year variations over the 1997-2006 period.

During 1997-2006, the contribution of surface heat fluxes to intraseasonal SST variability averaged over the TRIO region in the model is $70 \%$, against $20 \%$ due to wind-stress-induced 
entrainment and vertical advection. The heat-flux-induced intraseasonal SST variability is dominated by shortwave variations ( $75 \%$ ), with other components of the heat flux playing a more modest role (25\%). Estimates from an independent heat flux product suggest a similar contribution of other flux components $(32 \%)$. The time scale of the heat-flux perturbation, in addition to its amplitude, is also important in controlling the intraseasonal SST signature, with longer periods favouring a larger response.

There are also strong year-to-year variations in the relative importance of heat-flux and windstress forcing. There are 5 clear cooling events during the record covered by both the model and observations: 2 in 1999 (Harrison and Vecchi 2001, Duvel et al. 2004), one in 2000, one in 2001 and the strongest event in 2002 (Vinayachandran and Saji, 2008). Amongst these events, there is one occurrence (2000) where wind-stress driven SST signature dominate and one (2001) where it contributes significantly.

Interannual variations of the subsurface thermal structure associated with IOD/ENSO events modulate the MJO-driven SST signature by up to $30 \%$, mainly by changing the temperature of water entrained into the mixed layer. The main factor that controls year-to-year changes in amplitude of the SST response is hence the amplitude and time-scale of the surface heat flux perturbation.

As noted in Section 2, the model has some biases that might affect our results. First, its climatological mixed layer is somewhat too thin in the TRIO region during boreal winter $(21 \mathrm{~m}$ instead of $26 \mathrm{~m}$ ). As seen from equation (2), this bias could tend to increase the amplitude of the SST perturbation, but should affect both the heat-flux forcing (term a) and the entrainment, upwelling and mixing (term b) in a similar way. Therefore, it probably does not significantly affect our estimate of the respective influence of these two processes.

An important factor in controlling the amplitude of subsurface oceanic processes (entrainment, upwelling, mixing) is the temperature stratification below the mixed layer. Figure 2 suggests that, although the model stratification is too diffuse at depth, it is quite reasonable just below the mixed layer. On the other hand, comparisons with observations (Section 2c) suggest that the model forcing underestimates intraseasonal variability of the wind stress by $\sim 30 \%$, which could result in an underestimation of the model response by the same amount, to the extent that the ocean response is linear. Additionally, we showed that there is a $\sim 10 \%$ error in our estimate of the contribution of heat fluxes / wind stress contribution to intraseasonal SST variability. Even if we add these two, our estimate of the contribution of heat flux variability is large enough $(70 \%)$ to remain the dominant process in controlling TRIO intraseasonal SST variability over the whole period. We should point 
out, however, that vertical oceanic processes are not negligible on average, and can even dominate the heat budget on particular years (e.g., 2001), or locally at various locations within the TRIO region.

Last but not least, our model has a $1^{\circ}$ horizontal resolution and hence does dot resolve eddy variability outside of the equatorial band. This is probably the reason why SST intraseasonal variability is underestimated at several locations (figure 3). We are however mostly concerned with large scale processes, in this paper. The SST perturbations associated with the MJO are comparable to the size of the "TRIO" box we are using, which is $~ 3300 \mathrm{~km} \times 550 \mathrm{~km}$ (e.g., Harrison and Vecchi, 2001; Duvel et al. 2004). The Rossby radius in this region varies between 100 and $200 \mathrm{~km}$ (Chelton et al., 1998, JPO vol 28, 433-460). The region we consider hence has 15 to 25 times the typical size of eddies in this region. Whereas the model undoubtedly underestimates eddy fluxes at small scales, a large portion of these eddy fluxes is unstructured in space and should average to zero at the scale of the MJO oceanic signature itself. We therefore feel that the model resolution should not affect strongly our quantitative estimates of processes contributing to the SST signature of the MJO other than through its impact on the mean state of the model.

Our model-derived estimate of the influence of heat fluxes on intraseasonal SST perturbations in the TRIO region is $70 \%$, while our observational estimate based on the TropFlux product is only $52 \%$. We saw in section 4 that the "slab mixed layer" approach that we used to obtain our observational estimate was probably not a major source of error (about 4-5\%). The correlation between the intraseasonal SST and time-integrated intraseasonal heat flux is excellent $(0.86)$ and Praveen Kumar et al. (2010) report of 15-20\% underestimation of TropFlux (and OAFLUX) daily heat fluxes against the more precise estimates obtained from the RAMA moorings. We therefore suggest that the lower contribution of fluxes in our observational estimate originates from underestimation of net heat flux intraseasonal variability by Tropflux.

Most previous studies did not quantify precisely the relative role of heat fluxes and wind-stress driven entrainment and mixing, but rather provided qualitative assessments of their importance. The case study of Harrison and Vecchi (1999) for the January 1999 cooling event suggested that vertical oceanic processes dominated the cooling, whereas Duvel et al. (2004) concluded that heat fluxes were the dominant factor for the same event. The present study does not allow drawing a conclusion: observations suggest a 30\% contribution of heat fluxes (Figure 5a), while the model suggests a $70 \%$ contribution for that event (Figure 9a). Vinayachandran and Saji (2008) suggested that vertical oceanic processes dominated the response in 2000 and air-sea fluxes in 2002, in agreement with the present study (Figure 9a). For the late 2007-early 2008 event, Vialard et al. (2008) from in situ 
observations report that surface heat flux was the main contributor. The results from the TropFlux product suggest a smaller influence of heat fluxes (48\%; Figure 5a), but this difference is probably due to the underestimated heat flux perturbation in the TropFlux product. The intraseasonal heat flux perturbation is indeed $\sim 120 \mathrm{Wm}^{-2}$ peak-to-peak in Figure $5 \mathrm{~b}$, against $>200 \mathrm{~W} . \mathrm{m}^{-2}$ for the 2006-2007 event studied in Vialard et al. 2008, consistent with the underestimation of heat-flux variability by TropFlux mentioned in the previous paragraph.

The Saji et al. (2006) study covers a longer period than the cases studies above (1998-2005) but only provides a qualitative estimate, and concludes that "reduced solar radiation, enhanced evaporation and possibly strong entrainment over the thermocline ridge all play a role in the SST cooling”. Duvel and Vialard (2007) cover a similar period and mostly underline the role of air-sea fluxes, but again qualitatively. Han et al. (2007) made a very comprehensive study of the processes of intraseasonal SST variability in boreal winter in the Indian Ocean, including quantitative estimates. Their results are difficult to compare to ours, however, because they use a different partition in terms of processes (their evaluation of the wind effect includes wind-driven latent heat flux variations, and the wind - rather than wind stress - is also used in the mixed layer scheme in their model). In one aspect, their conclusions differ markedly from ours. In their simulations, the shortwave radiation has no influence on intraseasonal SST variations in the TRIO region. This result is really quite surprising, given the large-amplitude, surface-heat-flux perturbations due to shortwave radiation that are observed in the Indian Ocean (e.g., Section 3, Shinoda and Hendon 1998, Vialard et al. 2008). We therefore believe our result giving a significant importance (about $50-60 \%$ of the total SST variability) to the shortwave-radiation perturbation is in better agreement with previous studies.

The only study that provides a quantitative estimate comparable to ours is Lloyd and Vecchi (2010). Although they focus on shorter timescale cooling events ( $<30$ days), they find a 75\% contribution of fluxes for SST events between 1.5 and 2.5 standard deviation, and 55\% for events above 2.5 standard deviation. Our estimate is consistent with theirs for moderate events. For the two events above 2.5 standard deviation in our time series (1997 and 2002), however, we find a dominant role of air-sea fluxes (Figure 9a). We agree with Resplandy et al. (2009) and Lloyd and Vecchi (2010) in that subsurface stratification modulates the relative importance of air-sea fluxes and vertical oceanic processes (with a shallow thermocline favouring a stronger role of the latter), which may explain part of the disagreement amongst past case studies. Our quantitative estimate over the 1997-2006 period however suggests that the impact of this modulation on intraseasonal SST amplitude is rather weak $(\sim 30 \%)$ and that the amplitude and phasing of the heat flux perturbation is 
the main factor that controls the amplitude of its SST signature. In that respect, it is useful to note that Izumo et al. (2010) proposed that interannual variability of the atmospheric background state over the Indian Ocean modulates the properties (latitude and timescale) of the MJO over the Indian Ocean. If this idea is correct, there might indeed be a control of the amplitude of the MJO signature in the TRIO region by interannual variability in the Indian Ocean, but through changes in the surface heat flux perturbation properties rather than changes in the subsurface ocean thermal state.

We feel that with a consensus on the processes controlling the MJO SST signature drawing near, it is now possible to focus on its potential feedback onto the atmosphere. There has indeed been a wide range of studies showing a moderate impact of coupling on the MJO (e.g. Waliser et al. 1999, Inness et al. 2003a, Maloney and Sobel 2004), but none of them reproduced the relatively large amplitude SST signature of the MJO in the TRIO region and North-Western Australian Basin (e.g., Duvel and Vialard 2007). The potential feedback of the MJO SST signature on the MJO itself hence needs to be re-examined with models that reproduce better the large SST perturbations in these regions.

Acknowledgements: A. Jayakumar and Praveen Kumar B. thank Council of Scientific and Industrial Research (CSIR), India for Junior/Senior Research Fellowships. Jérôme Vialard and Matthieu Lengaigne are funded by Institut de Recherche pour le Développement (IRD) and made their contributions to this paper while visiting the National Institute of Oceanography (NIO) in Goa, India. This is NIO contribution number xxx. Financial support of Space Application Centre (SAC), Ahmedabad, India and Indian National Centre for Ocean Information Services (INCOIS), Hyderabad, India is acknowledged. TMI gridded SST data are produced by Remote Sensing Systems and are available at www.remss.com. The altimeter products were produced by Salto/Duacs and distributed by AVISO with support from CNES. The wind stress data were obtained from CERSAT, at IFREMER, Plouzané (France). 


\section{References}

Bellenger, H., J.-P. Duvel, M. Lengaigne, and P. Levan (2009), Impact of organized intraseasonal convective perturbations on the tropical circulation, Geophys. Res. Lett., 36, L16703, doi:10.1029/2009GL039584.

Bentamy A., K B. Katsaros, M. Alberto, W. M. Drennan, E. B. Forde, and H. Roquet, 2003: Satellite Estimates of wind speed and latent heat flux over the global oceans, J. Climate, 16, 637-656.

Bryan K, Lewis LJ, 1979: A water mass model of the world ocean, J. Geophys. Res., 84, 2502-2517

Chelton, D.B., R. A. deSzoeke, M.G. Schlax, K. El Naggar and N. Siwertz, 1998: Geographical Variability of the First Baroclinic Rossby Radius of Deformation, J. Phys. Oceanogr., 28, 433460.

Chowdary, J.S., C. Gnanaseelan and S.P. Xie, 2009: Westward propagation of barrier layer propagation in the 2006-07 Rossby wave event over the tropical southwest Indian Ocean, Geophys. Res. Lett., 36, L04607, 1-5.

de Boyer Montégut, C., G. Madec, A. S. Fischer, A. Lazar, and D. Iudicone (2004), Mixed layer depth over the global ocean: An examination of profile data and a profile-based climatology, $J$. Geophys. Res., 109, C12003, doi:10.1029/2004JC002378.

Dee, D. P., and S. Uppala, 2009: Variational bias correction of satellite radiance data in the ERAInterim reanalysis. Quart. J. R. Meteorol. Soc., 135, 1830-1841.

Duvel, J-P. and J. Vialard, 2007, Indo-Pacific Sea Surface Temperature Perturbations Associated with Intraseasonal Oscillations of the Tropical Convection, Journal of Climate, 20, 3056-3082.

Duvel, J-P., R. Roca and J. Vialard, 2004, Ocean Mixed Layer Temperature Variations induced by Intraseasonal Convective Perturbations over the Indian Ocean. J. Atm. Sciences, 61, 10041023.

Fairall, C. W., E. F. Bradley, D. P. Rogers, J. B. Edson, and G. S. Young, 1996: Bulk parameterization of air-sea fluxes for Tropical Ocean-Global Atmosphere Coupled OceanAtmosphere Response Experiment. J. Geophys. Res., 101, 3747-3764.

Foltz, G. R., J. Vialard, Praveen Kumar B. and M. J. McPhaden, 2010 : Seasonal mixed layer heat balance of the southwestern tropical Indian Ocean, J. Clim., 23, 947-965. 
Gnanaseelan, C. and B.H. Vaid, 2010, Interannual variability in the Biannual Rossby waves in the tropical Indian Ocean and its relation to Indian Ocean Dipole and El Nino forcing, Ocean Dynamics, 60, 27-40, DOI 10.1007/s10236-009-0236-z

Griffies SM, Hallberg RW, 2000, Biharmonic friction with a Smagorisky viscosity for use in large scale eddy- permitting ocean models, Mon. Wea. Rev., 128, 2935-2946

Han, W., D. Yuan, W. T. Liu, and D. J. Halkides, 2007, Intraseasonal variability of Indian Ocean sea surface temperature during boreal winter: Madden-Julian Oscillation versus submonthly forcing and processes, J. Geophys. Res., 112, C04001, doi:10.1029/2006JC003791.

Harrison, D. E., and G. A. Vecchi, 2001: January 1999 Indian Ocean cooling event. Geophys. Res. Lett., 28, 3717-3720.

Hermes, J.C. and C.J.C. Reason, 2008: Annual cycle of the South Indian Ocean (Seychelles-Chagos) thermocline ridge in a regional ocean model, J. Geophys. Res., 113, C04035, doi:10.1029/2007JC004363.

Inness, P. M., and J. M. Slingo, 2003: Simulation of the Madden-Julian oscillation in a coupled general circulation model. Part I: Comparison with observations and an atmosphere-only GCM. J. Climate, 16, 345-364.

Izumo,T., S. Masson, J. Vialard, C. D. Montegut, S.K.Behera, G. Madec, K. Takahashi and T. Yamagata, 2010, Low and high frequency Madden Julian Oscillation in Austral summer Interannual variations, Climate Dynamics, in press.

Kalnay et al.,The NCEP/NCAR 40-year reanalysis project, Bull. Amer. Meteor. Soc., 77, 437-470, 1996.

Kanamitsu M., W. Ebisuzaki, J. Woollen, S-K Yang, J.J. Hnilo, M. Fiorino, and G. L. Potter, 2002, NCEP-DEO AMIP-II Reanalysis (R-2), Bul. of the Atmos. Met. Soc, 1631-1643.

Large WG, McWilliams JC, Doney SC (1994) Oceanic vertical mixing: A review and a model with a no local boundary layer parametrization, Rev. of Geophys, 32, 363-403.

Large WG, Yeager SG (2004) Diurnal to decadal global forcing for ocean and sea-ice models: The data sets and flux climatologies NCAR/TN-460+STR, 111.

Levitus S (1998) Climatological atlas of the world ocean, Tech Rep, NOAA, Rockville, Md. Roll, HV (1965) Physics of the Marine Atmosphere, Academic Press, New York 426pp. 
Liebmann, B., and C. A. Smith, 1996 : Description of a complete (interpolated) outgoing longwave radiation dataset. Bull. Amer. Meteor. Soc., 77, 1275-1277.

Lloyd, I. D. and G. A. Vecchi, 2009: Submonthly Indian Ocean Cooling Events and their Interaction with Large-Scale Conditions. J. Climate, doi:10.1175/2009JCLI3067.1

Locarnini, R. A., A. V. Mishonov, J. I. Antonov, T. P. Boyer, and H. E. Garcia, 2006: World Ocean Atlas 2005, Volume 1: Temperature. S. Levitus, Ed. NOAA Atlas NESDIS 61, U.S. Government Printing Office, Washington, D.C., 182 pp.

Maloney, E. D., and A. H. Sobel, 2004: Surface fluxes and ocean coupling in the tropical intraseasonal oscillation. J. Climate, $17,4368-4386$.

Masumoto Y., and G. Meyers, 1998: Forced Rossby waves in the southern tropical Indian Ocean. $J$. Geophys. Res. 103(C12):27589-27602

Matthews, A. J. (2004), The atmospheric response to observed intraseasonal tropical sea surface temperature anomalies, Geophys. Res. Lett., 31, L14107, doi:10.1029/2004GL020474.

McCreary, J. P., P. K. Kundu, and R. L. Molinari, 1993:A numerical investigation of dynamics, thermodynamics and mixed layer processes in the Indian Ocean. Prog. Oceanogr., 31, 181244.

McPhaden, M.J., G. Meyers, K. Ando,Y. Masumoto, V.S.N. Murty, M. Ravichandran, F. Syamsudin, J. Vialard, L. Yu, and W. Yu, 2009: RAMA: The Research Moored Array for African-AsianAustralian Monsoon Analysis and Prediction. Bull. Am. Meteorol. Soc., 90, 459-480.

Praveen Kumar B., J. Vialard, M. Lengaigne and V.S.N. Murty, 2010: A high-quality daily air-sea flux product in the tropics for the 1989-2009 period. To be submitted in Clim. Dyn.

Resplandy, L., J. Vialard, Y. Dandonneau, O. Aumont, M. Levy, 2009: Seasonal and intraseasonal biogeochemical variability in the thermocline ridge of the Indian Ocean,J. Geophys. Res., J. Geophys. Res., 114, C07024, doi:10.1029/2008JC005246.

Saji NH, Goswami BN, Vinayachandran PN, Yamagata T, 1999: A dipole mode in the tropical Indian Ocean. Nature, 401, 360-363

Saji, N. H., S.-P. Xie and C. Y. Tam, 2006: Satellite observations of intense intraseasonal cooling events in the tropical south Indian Ocean. Geophys. Res. Lett., 33, L14704, doi:10.1029/2006GL026525.

Satheesan, K., A. Sarkar, A. Parekh, M.R. Ramesh Kumar, and Y. Kuroda, 2007: Comparison of 
wind data from QuikSCAT and buoys in the Indian Ocean, Int. J. Rem. Sen., 10, 2375-2382.

Schott, F. A., S.-P. Xie, and J. P. McCreary Jr., 2009, Indian Ocean circulation and climate variability, Rev. Geophys., 47, doi:10.1029/2007RG000245.

Tozuka T, Yokoi T, Yamagata T (2009) Interannual Variations of the Seychelles Dome ,J.Geophys. Res., (Revised).

Sengupta, D., and M. Ravichandran, 2001: Oscillations of Bay of Bengal sea surface temperature during the 1998 summer monsoon. Geophys. Res. Lett., 28, 10, 2033-2036.

Shinoda, T., and H. H. Hendon, 1998: Mixed layer modeling of intraseasonal variability in the tropical western Pacific and Indian Oceans. J. Climate, 11, 2668-2685.

Thompson B, Gnanaseelan C, Parekh A, Salvekar PS (2008) North Indian Ocean warming and sea level rise in an OGCM. J Earth Sys Sci 169-178

Thompson B, Gnanaseelan C, Salvekar PS (2006) Variability in the Indian Ocean circulation and salinity and its impact on SST anomalies during dipole events. J Mar Res 64: 853- 880

Tsai, P.T.H., J.J. O’Brien, M.E. Luther, 1992: The 26-day oscillation observed in the satellite sea surface temperature measurements in the equatorial western Indian Ocean. J. Geophys. Res., 31, 9605-9618.

Vialard, J., G. Foltz, M. McPhaden, J-P. Duvel and C. de Boyer Montégut, 2008, Strong Indian Ocean sea surface temperature signals associated with the Madden-Julian Oscillation in late 2007 and early 2008, Geophys. Res. Lett., 35, L19608, doi:10.1029/2008GL035238.

Vialard, J., J-P. Duvel, M. McPhaden, P. Bouruet-Aubertot, B. Ward, E. Key, D. Bourras, R. Weller, P. Minnett, A. Weill, C. Cassou, L. Eymard, T. Fristedt, C. Basdevant, Y. Dandoneau, O. Duteil, T. Izumo, C. de Boyer Montégut, S. Masson, F. Marsac, C. Menkes, S. Kennan, 2009a, Cirene: Air Sea Interactions in the Seychelles-Chagos thermocline ridge region, Bull. Am. Met. Soc., 90, 45-61.

Vinayachandran, P. N., and N. H. Saji, 2008, Mechanisms of South Indian Ocean intraseasonal cooling. Geophys. Res. Lett., 35, L23607, doi:10.1029/2008GL035733.

Waliser, D. E., K. M. Lau, and J.H. Kim, 1999, The influence of coupled SSTs on the MaddenJulian oscillation: a model perturbation experiment. J. Atmos. Sci., 56, 333-358.

Wentz, F.J., C. Gentemann, D.Smith, D.Chelton, 2000: Satellite measurements of sea-surface temperature through clouds. Science, 288, 847-850. 
Wheeler, M.C. and H.H. Hendon, 2004: An all-season real-time multivariate MJO index: Development of an index for monitoring and prediction. Mon. Wea. Rev., 132, 1917-1932.

Woolnough, S. J., F. Vitart, and M. A. Balmaseda, 2007: The role of the ocean in the Madden-Julian Oscillation: Sensitivity of an MJO forecast to ocean coupling. Quart. J. Roy. Meteor. Soc., $133,117-128$.

Xie, S.-P., H. Annamalai, F.A. Schott and J.P. McCreary, 2002: Structure and mechanisms of south Indian climate variability, J. Climate, 9, 840-858.

Yokoi, T., T. Tozuka, and T. Yamagata, 2008, Seasonal variation of the Seychelles Dome, J. Climate, 21, 3740-3754.

Yu, W., B. Xiang, L. Liu, and N. Liu, 2005: Understanding the origins of interannual thermocline variations in the tropical Indian Ocean, Geophys. Res. Lett., 32, L24706, doi:10.1029/2005GL024327.

Yu, L., and R. A. Weller, 2007: Objectively Analyzed air-sea heat Fluxes (OAFlux) for the global oceans. Bull. Ameri. Meteor. Soc., 88, 527-539.

Zhang, C., 2005: The Madden Julian Oscillation, Rev. Geophys., 43, RG2003, doi:10.1029/2004RG000158.

Zhang, Y., W. B. Rossow, A. A. Lacis, V. Oinas, and M. I. Mishchenko, 2004: Calculation of radiative fluxes from the surface to top of atmosphere based on ISCCP and other global data sets: Refinments of the radiative trasfer model and the input data. J. Geophys. Res., 109, D19105, doi:10.1029/2003JD004457

Zhou, L., R. Murtugudde, and M. Jochum, 2008: Dynamics of the intraseasonal oscillations in the Indian Ocean South Equatorial Current. J. Phys. Oceanogr., 38, 121-132. 
Table 1. List of experiments used in this study.

\begin{tabular}{|l|l|}
\hline \multicolumn{1}{|c|}{ Name } & \multicolumn{1}{|c|}{ Description } \\
\hline CTL & Full forcing. \\
\hline NO_ISO_FLX & $\begin{array}{l}\text { Low-passed filtered shortwave and non-solar heat } \\
\text { fluxes. }\end{array}$ \\
\hline NO_ISO_SW & Low passed filtered shortwave flux \\
\hline NO_ISO_STRESS & Low passed filter wind stress \\
\hline NO_ISO & $\begin{array}{l}\text { Low passed filtered shortwave and non-solar heat } \\
\text { fluxes, Low passed filtered wind stress }\end{array}$ \\
\hline NO_INT_STRESS & $\begin{array}{l}\text { Climatological wind stress }+ \text { high passed filtered } \\
\text { wind stress (suppresses interannual wind stress } \\
\text { variability) }\end{array}$ \\
\hline
\end{tabular}


Table 2. Estimates of the importance of the various processes in December-March over the TRIO region. The first column gives the standard deviation of 30-100 day filtered SST averaged over the TRIO region in observations, the CTL experiment, and then associated to various processes (see text for details). The second column gives the regression coefficient of the 30-100 day SST variability averaged over the TRIO region associated with each process to total 30-120 day variability in the CTL experiment. For the last line, the regression coefficient is given with respect to the estimate of heat flux-induced intraseasonal SST variability (i.e. the proportion of the heat flux-driven intraseasonal variability which is driven by shortwave flux). Note that by construction, the sum of the contribution of residual, error, wind stress and heat flux regression coefficients is equal to 1 (i.e., those can be seen as estimates of the percentage of variability explained by a certain process).

\begin{tabular}{|l|c|c|}
\hline \multicolumn{1}{|c|}{ Process } & $\begin{array}{c}\text { Amplitude of DJFM 30- } \\
\text { 100 day SST }\left({ }^{\circ} \mathrm{C}\right)\end{array}$ & $\begin{array}{c}\text { Contribution to total } \\
\text { variability (no unit) }\end{array}$ \\
\hline $\begin{array}{l}\text { All processes } \\
\text { (observations) }\end{array}$ & 0.27 & 1.00 \\
\hline $\begin{array}{l}\text { All processes } \\
\text { (CTL experiment) }\end{array}$ & 0.28 & 0.02 \\
\hline $\begin{array}{l}\text { Residual (filtering error and } \\
\text { internal variability) }\end{array}$ & 0.07 & 0.09 \\
\hline $\begin{array}{l}\text { Error (uncertainties in the } \\
\text { estimation of each processes due } \\
\text { to non-linearities) }\end{array}$ & 0.05 & 0.19 \\
\hline Wind stress & 0.12 & 0.70 \\
\hline Heat Flux & 0.22 & $0.75^{*}$ \\
\hline Shortwave flux & & \\
\hline
\end{tabular}


a) $\tau_{x}$ in CTL, NO_ISO_STRESS and ERS/Qscat

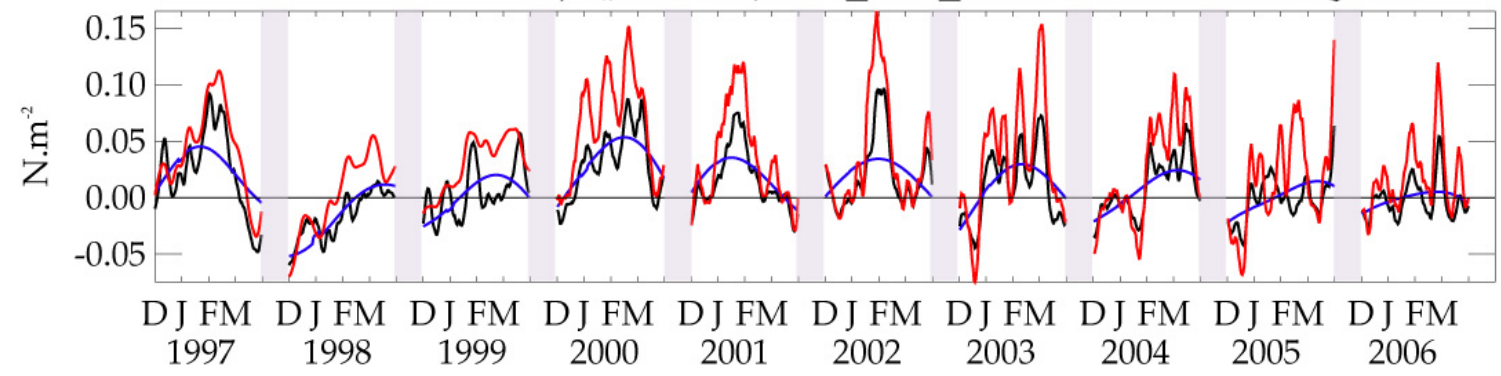

b) net heat flux in CTL, NO_ISO_FLX and TropFlux

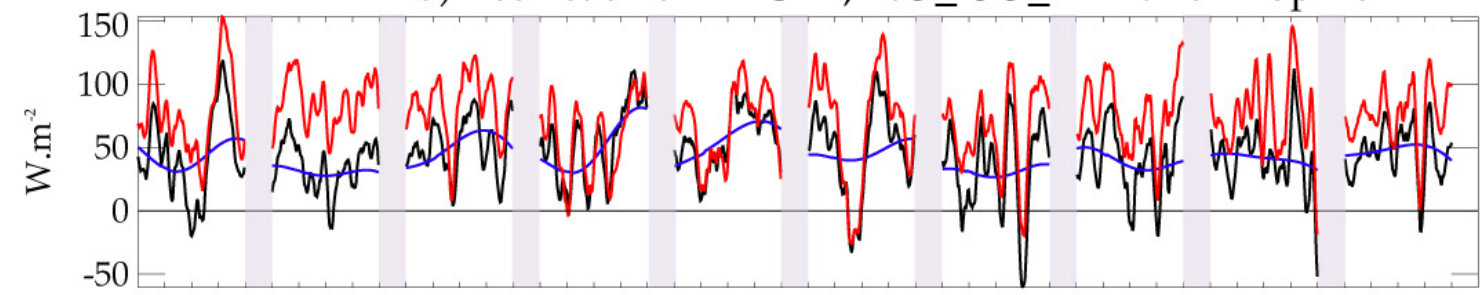

D J FM D J FM D J FM D J FM D J FM D J FM D J FM D J FM D J FM D J FM

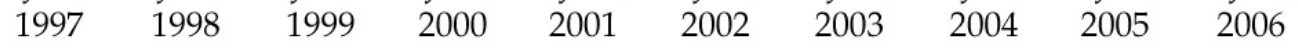

c) shortwave flux in CTL, NO_ISO_FLX/NO_ISO_SW and TropFlux

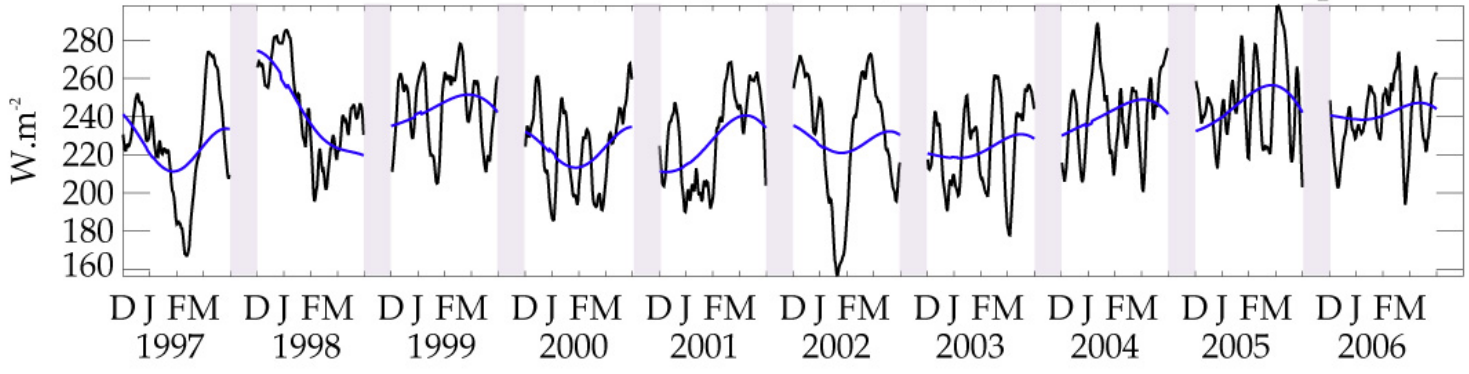

Figure 1. Average forcing fields of the CTL (black line) and 120-day low passed sensitivity experiments (blue line) within the TRIO region. The red line on $\mathrm{a}, \mathrm{b}$ indicates our best guess of actual stresses (from ERS and Qscat scaterometers) and net heat fluxes (from the TropFlux product). a) Zonal wind stress for CTL and ISO_FLX experiment. b) net heat flux for CTL and ISO_STRESS experiment and c) shortwave heat flux for CTL and ISO_LAT experiment. Only the DecemberMarch values have been plotted to focus on the period with the strongest SST intraseasonal events. Grey bars separate the different years in this plot. 
a) DJFM MLD (CTL experiment)

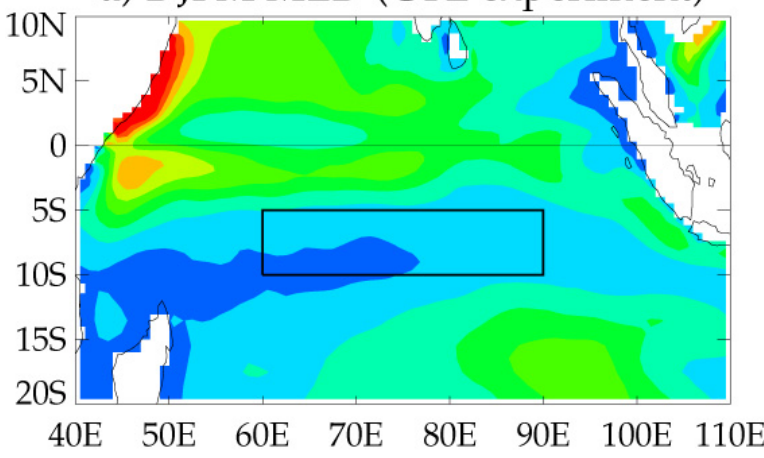

b) DJFM MLD (de Boyer et al. 2004)

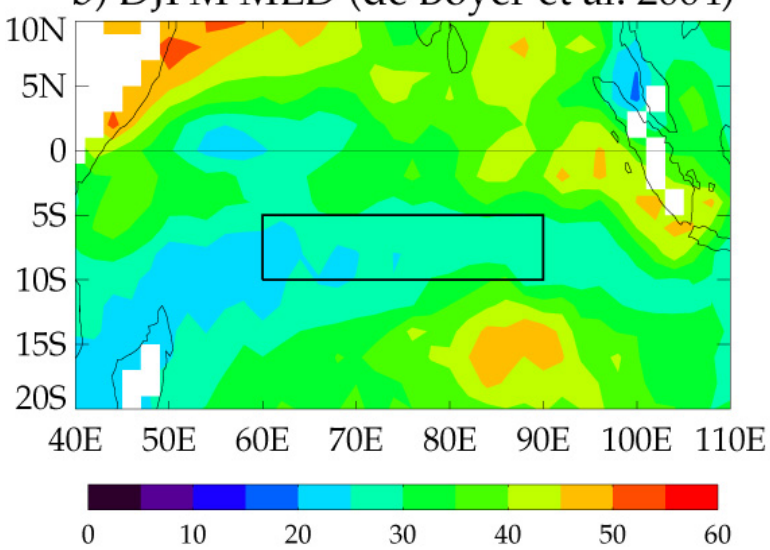

\section{c) DJFM T in TRIO region}

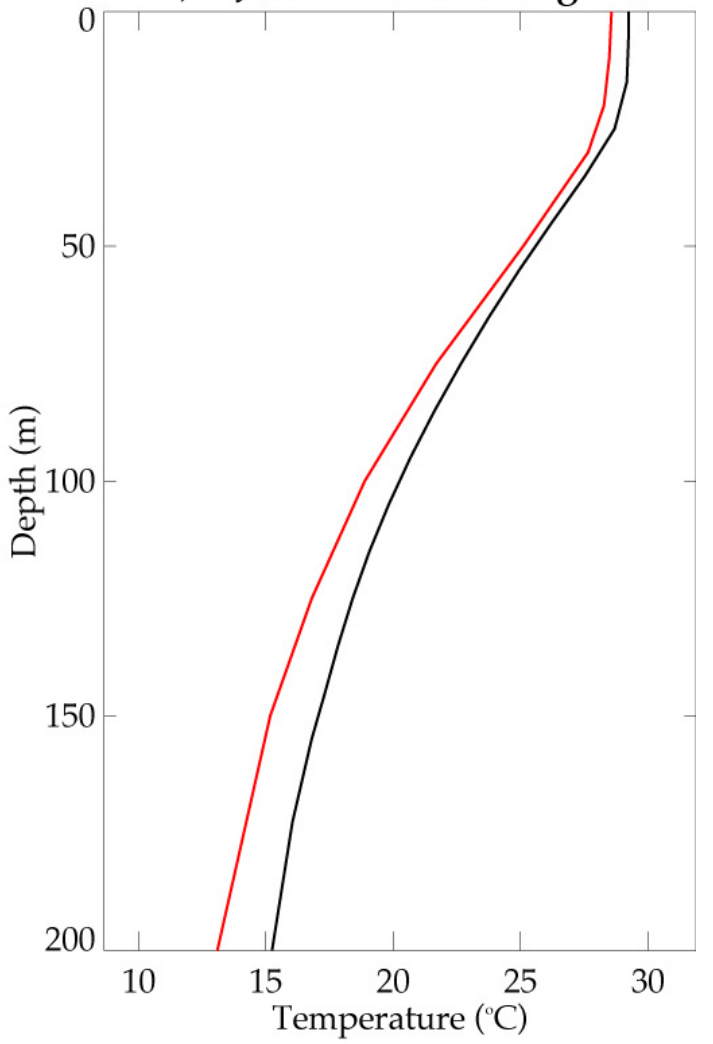

Figure 2. CTL experiment (a) and de Boyer et al. (2004) observed (b) December-March mixed layer depth climatology (m). CTL experiment (black) and WOA05 (red, Locarnini et al. 2006) DecemberMarch climatological temperature profile within the TRIO region (outlined in panels a,b). 


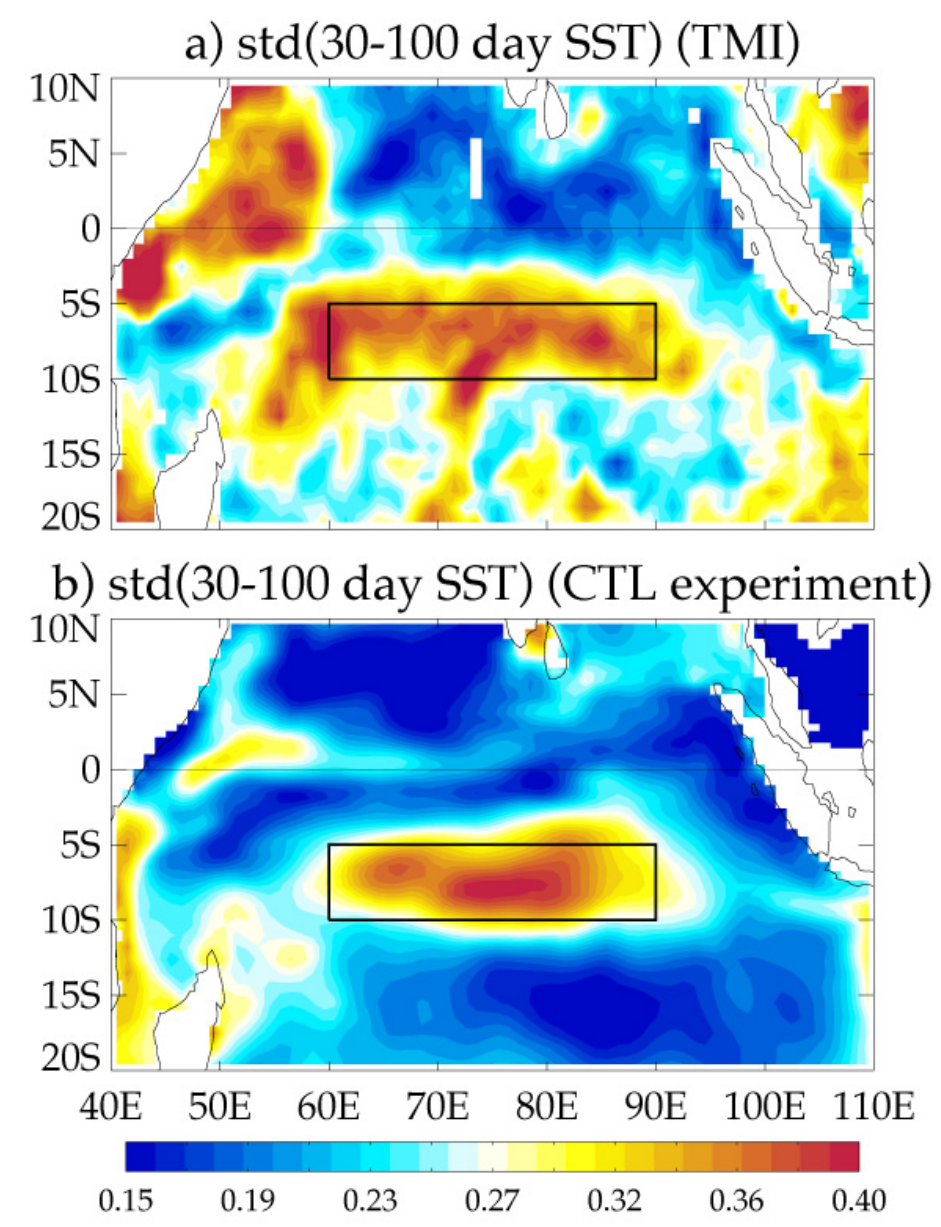

Figure 3. Standard deviation of 30-100 day band-passed SST for the December-March period during 1998-2006 $\left({ }^{\circ} \mathrm{C}\right)$ for a) TMI SST observations and b) CTL experiment. The black box indicates the TRIO $\left(60^{\circ} \mathrm{E}-90^{\circ} \mathrm{E}, 10^{\circ} \mathrm{S}-5^{\circ} \mathrm{S}\right)$ region used in this paper. 


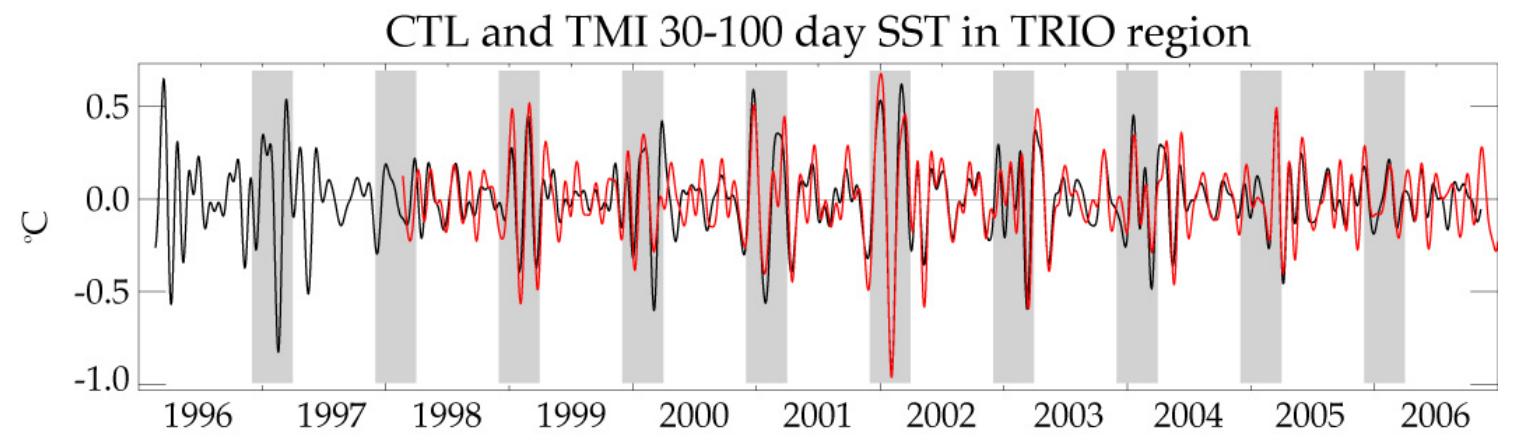

Figure 4. Average 30-100 day bandpassed SST within the TRIO $\left(60^{\circ} \mathrm{E}-90^{\circ} \mathrm{E}, 10^{\circ} \mathrm{S}-5^{\circ} \mathrm{S}\right)$ region (highlighted by a black box in figure 2) for the TMI SST observations (red) and CTL experiment (black). The grey shading highlights the December-March period which has the strongest SST intraseasonal variability associated with the MJO. 
a) 30-100 day TMI SST

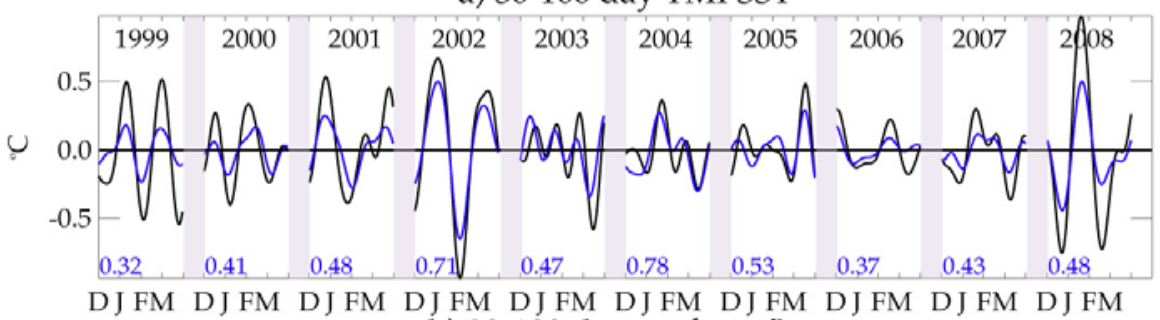

b) 30-100 day net heat flux

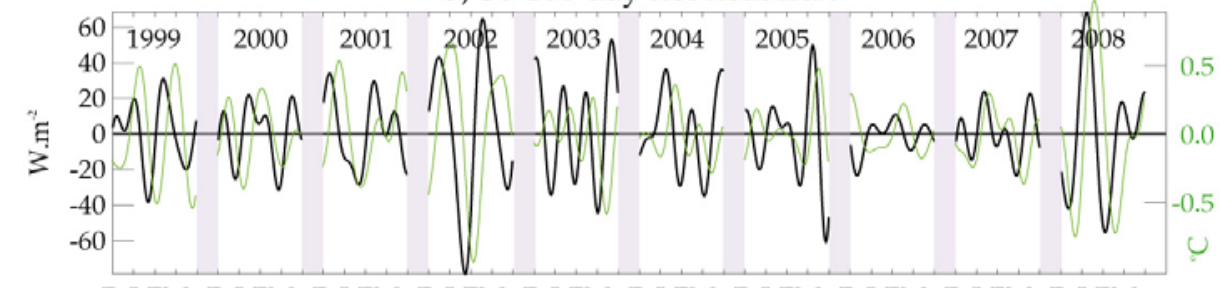

DJ FM DJ FM DJ FM DJFM DJFM DJFM DJFM DJFM DJFM DJFM

c) 30-100 day zonal wind stress

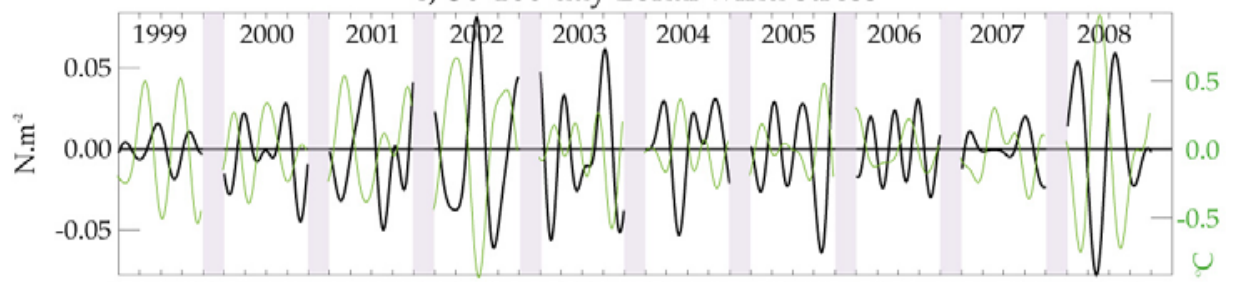

DJ FM DJ FM DJ FM DJ FM DJ FM DJFM DJ FM DJ FM DJ FM DJFM d) 30-100 day Ekman pumping velocity

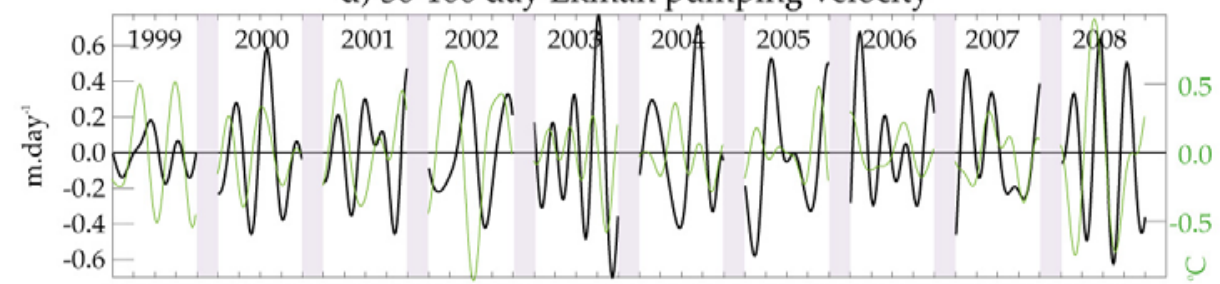

D J FM D J FM D J FM D J FM D J FM D J FM D J FM D J FM D J FM D J FM e) Dec-March average SLA

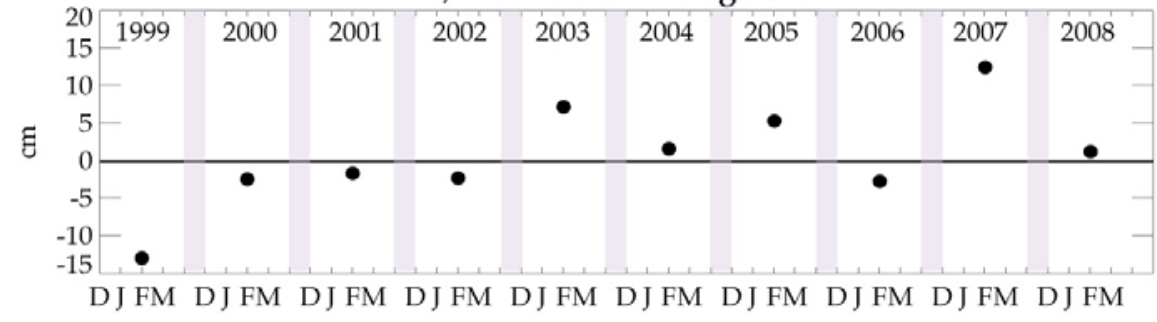

Figure 5 Observed 30-100 day bandpassed a) TMI SST (black) and expected response of a slab ocean mixed layer to air-sea flux perturbations in $\mathrm{b}$ (blue; ${ }^{\circ} \mathrm{C}$; the numbers under show the regression coefficient of the blue curve to the black one for each year). The TMI SST is also shown in green in panels b, c and d. b) net surface heat flux $\left(\mathrm{Wm}^{-2}\right)$, c) Qscat zonal wind stress $\left(\mathrm{N} \mathrm{m}^{-2}\right)$ and d) Qscat Ekman pumping $\left(\mathrm{m} \mathrm{day}^{-1}\right)$ in the TRIO region. Only the December-March values have been plotted to focus on the period with the strongest SST intraseasonal events. e) December-March average observed sea-level interannual anomaly $(\mathrm{cm})$ in the TRIO region. Grey bars separate the different years in this plot. 


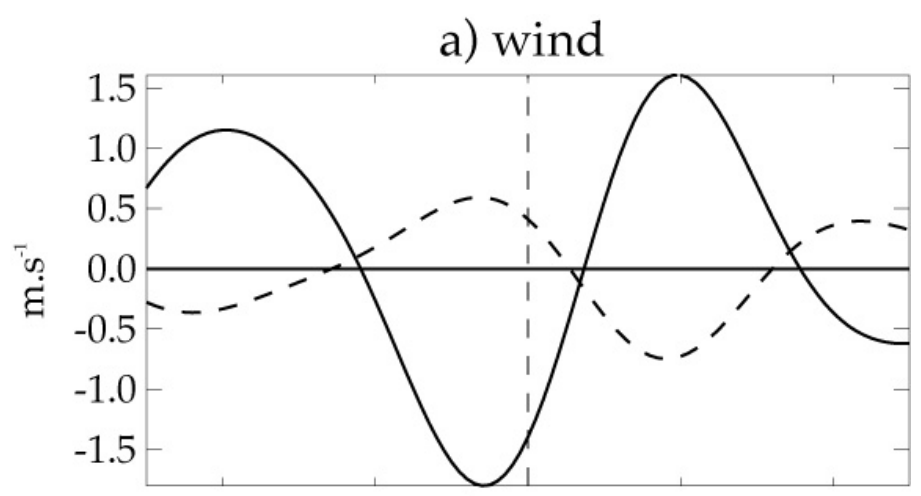

b) heat flux

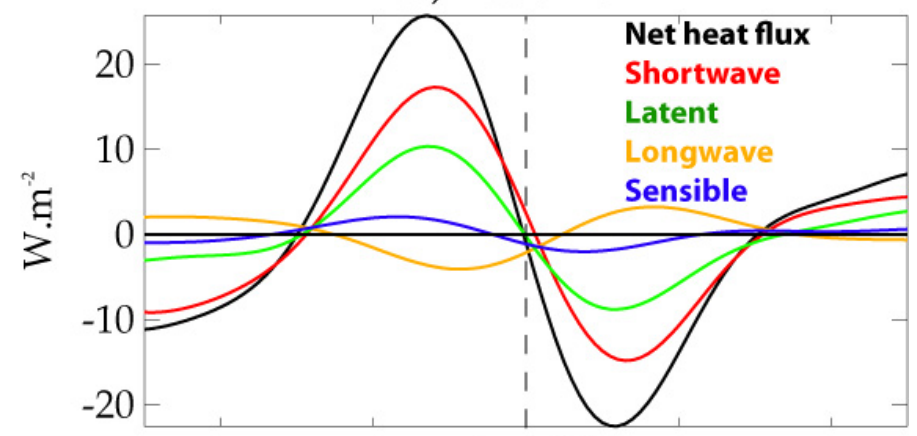

c) $\mathrm{SST}$

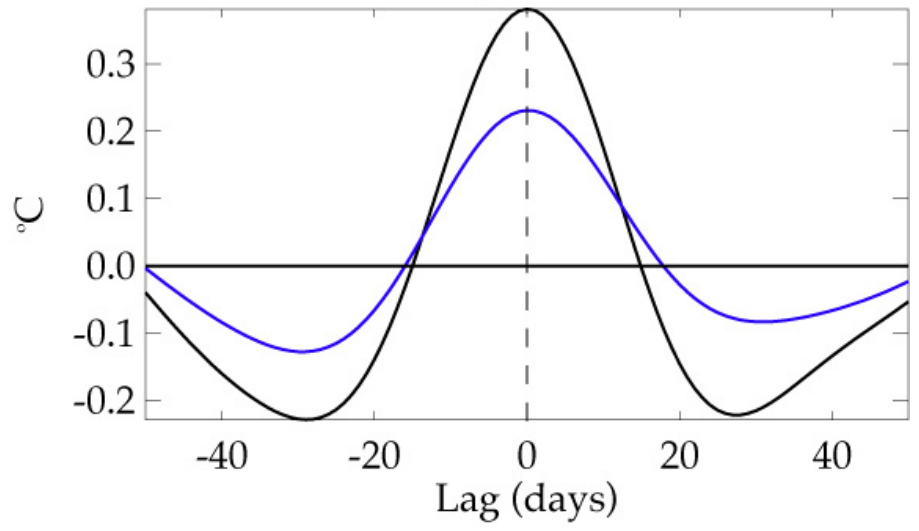

Figure 6. Intraseasonal (30-100 day) surface perturbations in the TRIO region regressed to 30-100 day band-passed SST in the TRIO region in Dece§mber-March: a) zonal (full line) and meridional (dashed line) wind $\left(\mathrm{m} \mathrm{s}^{-1}\right)$; b) Net heat flux (black) and its components $\left(\mathrm{W} \mathrm{m}^{-2}\right)$ and c) SST $\left({ }^{\circ} \mathrm{C}\right)$. The blue curve in c) shows the SST response of a slab ocean mixed layer to the net heat flux perturbation in b). 

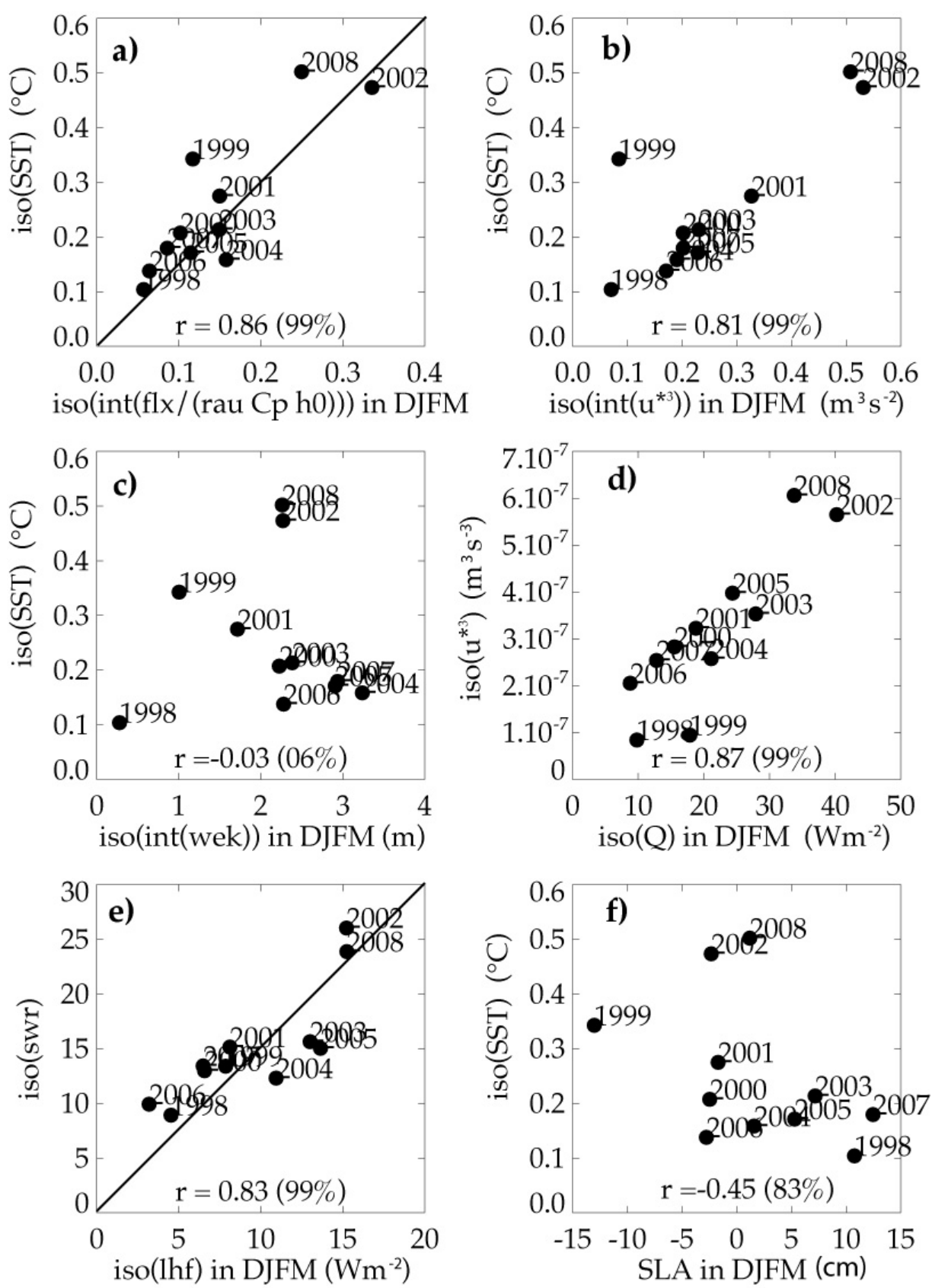

Figure 7. Scatterplot between observed amplitude of SST intraseasonal response each year $\left({ }^{\circ} \mathrm{C}\right.$, computed as the December-March standard-deviation of 30-100 day filtered SST) and a) amplitude of 30-100 day time-integral of the heat flux perturbation $\left({ }^{\circ} \mathrm{C}\right)$, b) amplitude of $30-100$ day time integral of the cube of friction velocity $\left(\mathrm{m}^{3} \mathrm{~s}^{-2}\right.$, see text for details), c) amplitude of 30-100 day time integral of Ekman pumping ( $\mathrm{m} \mathrm{day}^{-1}$ ) and $\mathrm{f}$ ) December-march average sea level anomaly in the TRIO region $(\mathrm{cm})$. d) scatterplot of 30-100 day cubed fiction velocity $\left(\mathrm{m}^{3} \mathrm{~s}^{-3}\right)$ against heat flux $\left(\mathrm{Wm}^{-}\right.$ $\left.{ }^{2}\right)$. e) scatterplot of 30-100 day surface shortwave $\left(\mathrm{Wm}^{-2}\right)$ against latent $\left(\mathrm{Wm}^{-2}\right)$ heat flux. The black line in figures $7 \mathrm{a}$ and $7 \mathrm{f}$ indicate the $\mathrm{y}=\mathrm{x}$ curve. The correlation and significance value are indicated at the bottom of each scatterplot. 


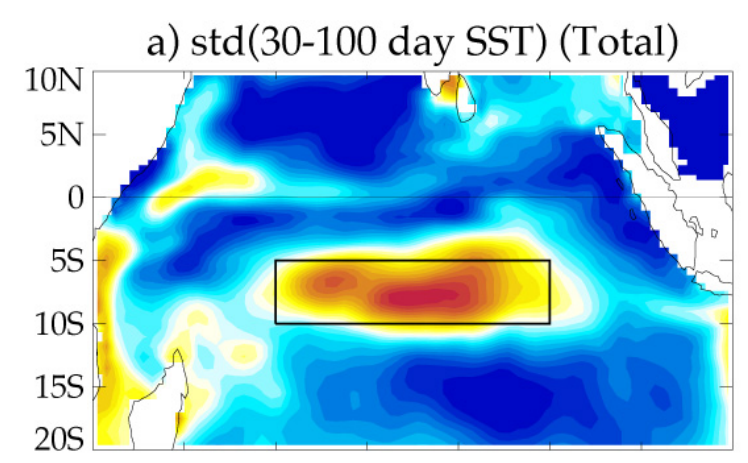

b) $\operatorname{std}(30-100$ day SST) (heat fluxes)
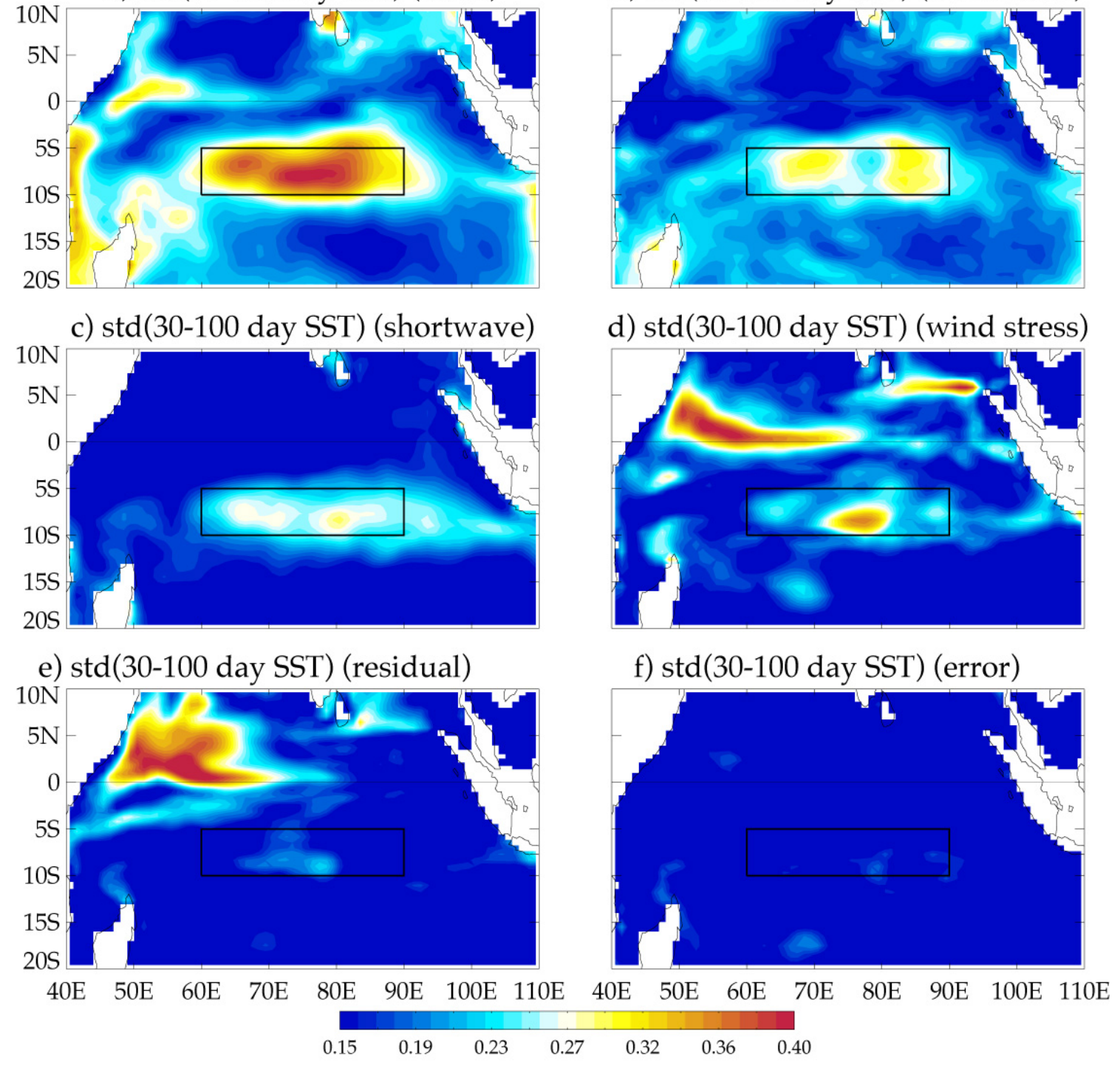

Figure 8. Standard deviation of December-March 30-100 band-passed SST for the 1999-2006 period: a) Total variability in CTL experiment and contributions from b) total heat flux, c) shortwave heat flux, d) wind stress, e) residual (representing both internal variability and filtering error due to spectral leaks from adjacent frequencies; see text for details) and f) error (mostly due to nonlinearities, see text for details). e) and f) can be combined to represent the overall uncertainty on the estimates of b), c), d). 
a) CTL, TAU (blue) and FLX (red) 30-100 day SST

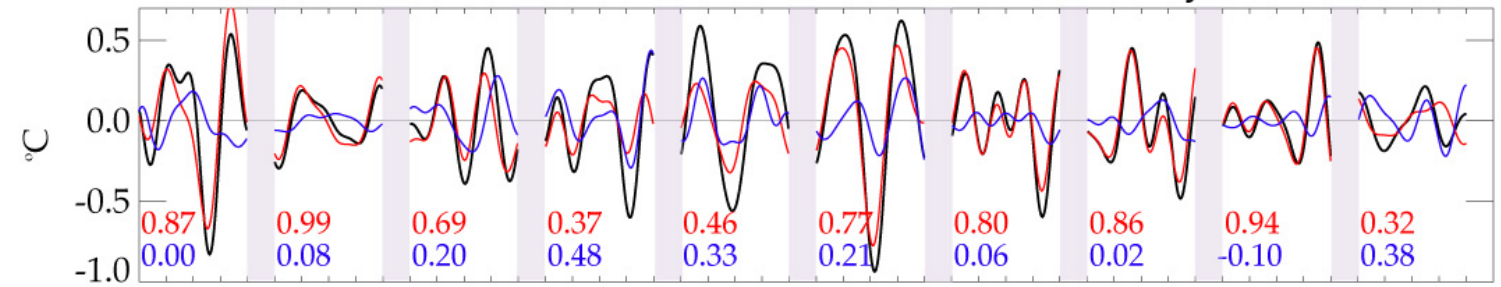

DJ FM DJ FM DJ FM DJ FM DJ FM DJ FM DJ FM DJ FM DJ FM DJ FM $\begin{array}{llllllllll}1997 & 1998 & 1999 & 2000 & 2001 & 2002 & 2003 & 2004 & 2005 & 2006\end{array}$

b) CTL, TAU+FLX (blue) 30-100 day SST

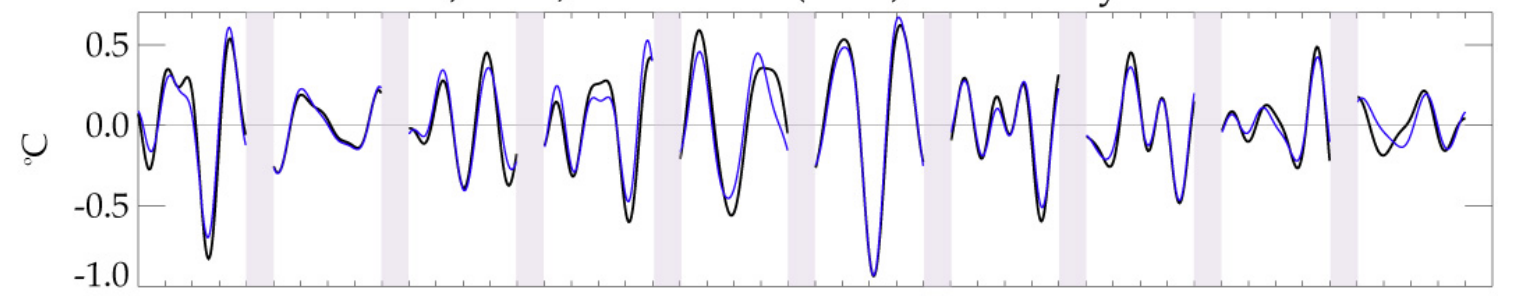

DJ FM DJFM DJ FM DJ FM DJ FM DJFM DJ FM DJ FM DJ FM DJ FM $\begin{array}{llllllllll}1997 & 1998 & 1999 & 2000 & 2001 & 2002 & 2003 & 2004 & 2005 & 2006\end{array}$

c) CTL, FLX (red) and slab mixed layer (blue) 30-100 day SST

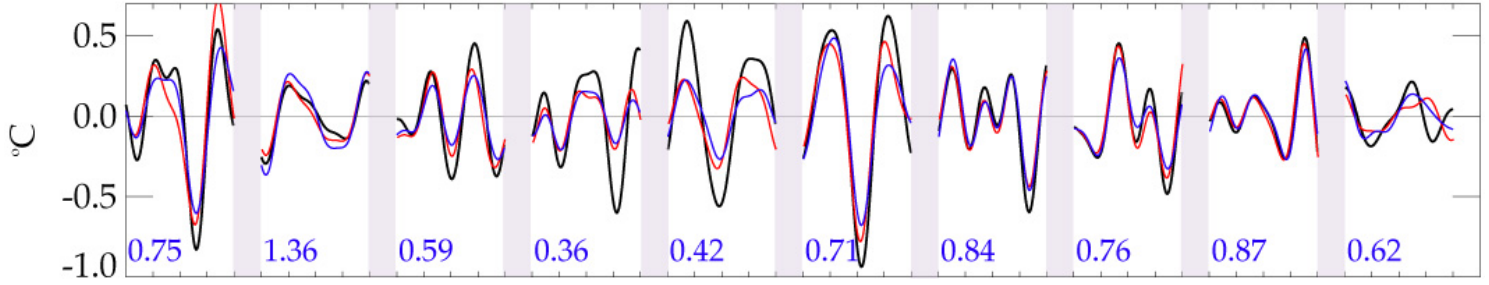

DJ FM DJ FM DJ FM DJ FM DJ FM DJ FM DJ FM DJ FM DJ FM DJ FM $\begin{array}{llllllllll}1997 & 1998 & 1999 & 2000 & 2001 & 2002 & 2003 & 2004 & 2005 & 2006\end{array}$

Figure 9. a) 30-100 day band-passed SST for CTL (black), wind stress contribution (blue) and heat flux contribution (red). b) 30-100 day band-passed SST for CTL (black) and sum of heat flux and wind stress contributions (blue). c) 30-100 day band-passed SST for CTL (black) and expected response from a slab ocean mixed layer (blue). In a) and c), the number indicated below each year are the regression coefficients of the 30-100 day SST in each experiment to the CTL experiment (i.e. the contribution of each process to total SST variability for each year). Only the December-March values have been plotted to focus on the period with the strongest SST intraseasonal events. Grey bars separate the different years in this plot. 


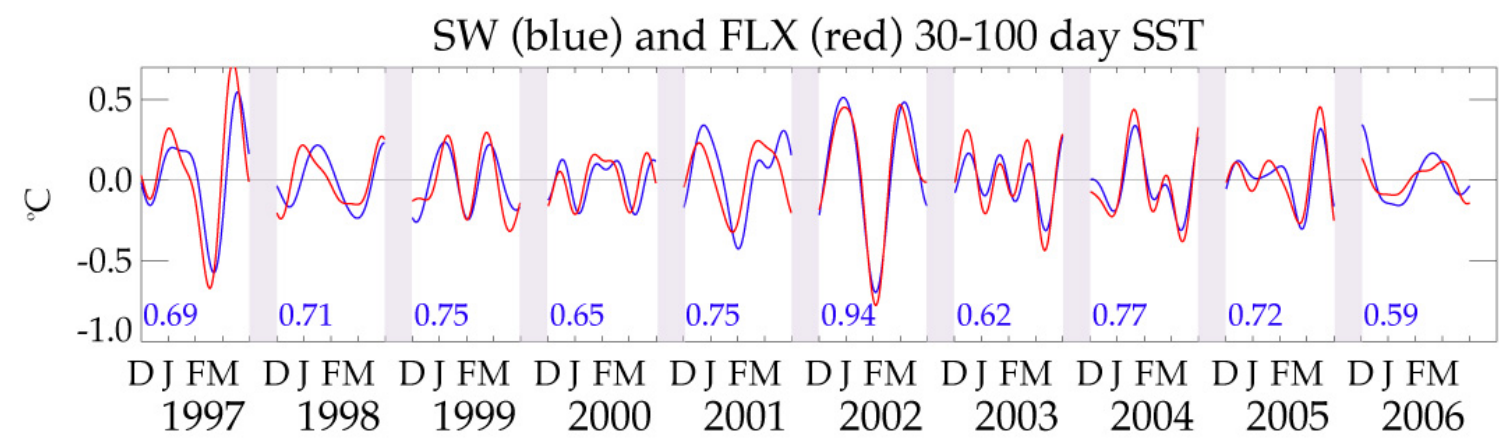

Figure 10. 30-100 day band-passed SST for total heat flux contribution (red) and ISO_shortwave contribution (blue). The numbers indicated below each year are the regression coefficients of the 30100 day shortwave contribution to the total heat flux contribution experiment (i.e. fraction of heat flux induced SST variability due to shortwave for each year). Only the December-March values have been plotted to focus on the period with the strongest SST intraseasonal events. Grey bars separate the different years in this plot. 


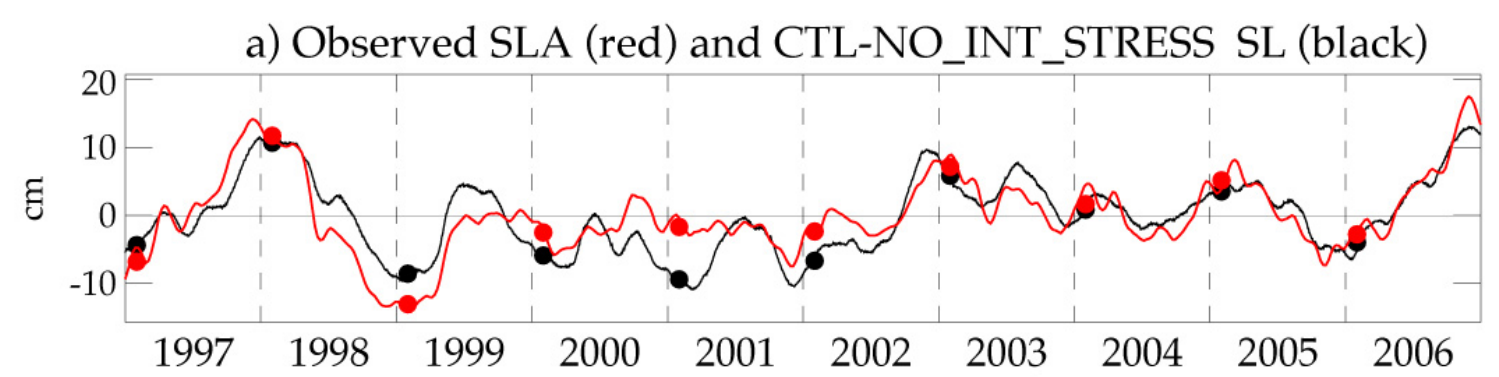

b) CTL and NO_INT_TAU (red) 30-100 day SST

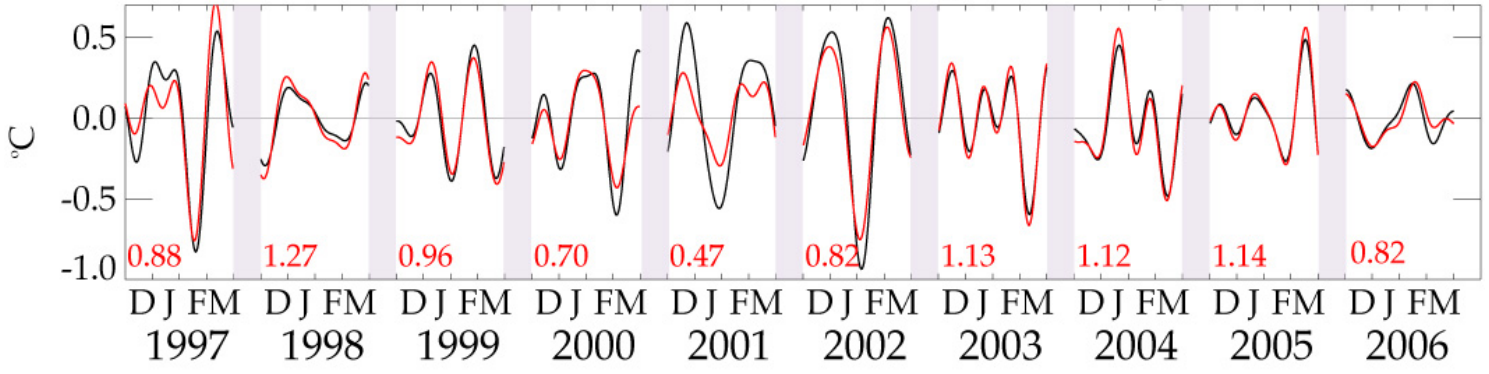

Figure 11. a) Observed sea level anomaly (red) and CTL-CLIM_TAU sea level in the TRIO region (black). The December-march average values are indicated by dots. b) CTL (black) and CLIM_TAU (red) 30-100 day band-passed SST in the TRIO region. The numbers indicated below each year are the regression coefficients of the 30-100 day SST in NO_INT_STRESS to the CTL experiment (i.e. an estimate of the impact of subsurface interannual variability on the SST response to the MJO). In b), only the December-March values have been plotted to focus on the period with the strongest SST intraseasonal events and grey bars separate the different years. 

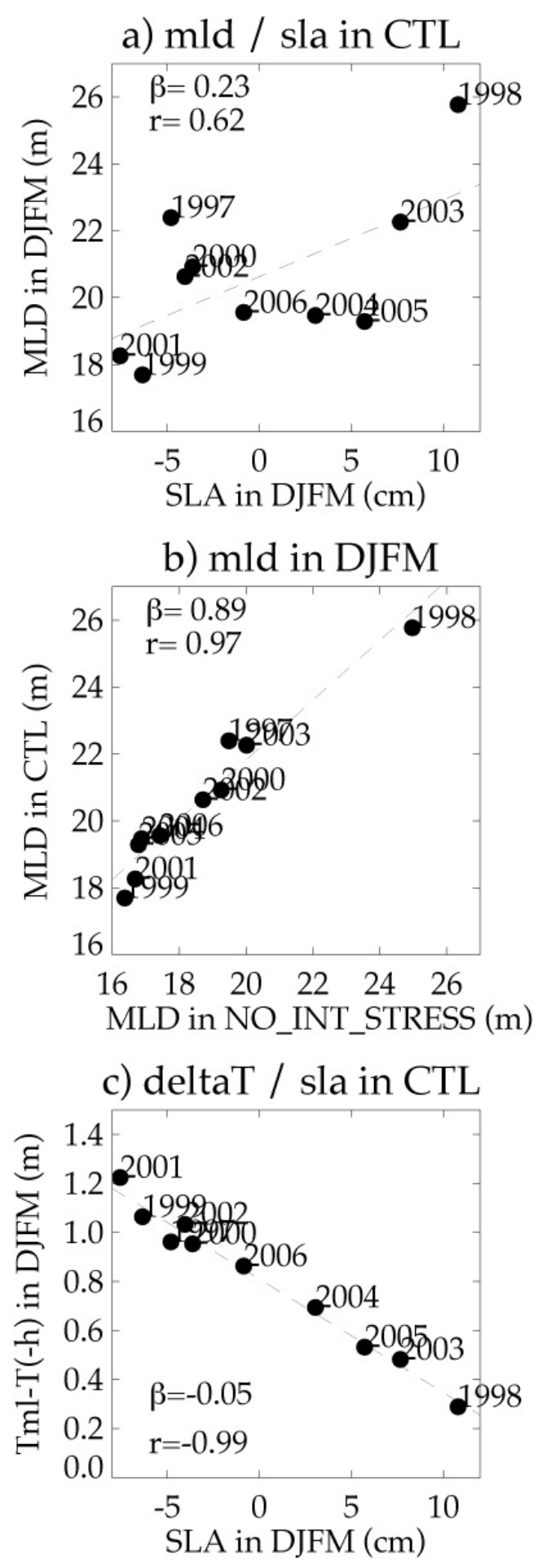

Figure 12. Scatterplot between December-March average mixed layer depth in the control experiment and a) December-March average sea level anomaly in the TRIO region in the CTL experiment and b) December-March average mixed layer depth in the CLIM_TAU experiment. c) Scatterplot between December-March average of temperature jump at the bottom of the mixed layer against sea level anomaly in the TRIO region. The slope of the regression $(\beta)$ and linear correlation coefficient (r) are indicated in each plot. 